\title{
Experimentally validated survey evidence on individual risk attitudes in rural Thailand
}

\author{
by Bernd Hardeweg, Lukas Menkhoff and Hermann Waibel
}

\author{
Discussion Paper No.464 \\ April 2012 (revised) \\ ISSN 0409-9962
}

\begin{abstract}
JEL-Classification: $\quad$ C93 (field experiment), D81 (decision-making under risk), O1 (economic development)

Keywords: $\quad$ field experiment, socio-economic survey, risk attitude, Thailand
\end{abstract}

We would like to thank participants at the Royal Economic Society Annual Conference 2010, at the European Economic Association Annual Conference 2010, at several university seminars, Oliver Gloede, Steven Humphrey, Sahra Sakha, Ulrich Schmidt, Andreas Wagener and two anonymous referees for very helpful comments. Financial support by the German Research Foundation (DFG) is gratefully acknowledged.

Bernd Hardeweg, Lukas Menkhoff*, Hermann Waibel; Department of Economics, Leibniz Universität Hannover, Königsworther Platz 1, D-30167 Hannover, Germany;

e-mail: hardeweg@ifgb.uni-hannover.de, menkhoff@gif.uni-hannover.de, waibel@ifgb.unihannover.de

* corresponding: Tel. ++49(0)511 7624552 


\title{
Experimentally validated survey evidence on individual risk attitudes in rural Thailand
}

\begin{abstract}
This study validates a survey-based measure of general risk attitude by an incentive compatible experiment with more than 900 participants in rural Thailand. The survey measure of self-assessed risk attitude provides a useful approximation of the experimentally derived risk attitude. This is further confirmed by adding various socio-demographic control variables taken from the representative household survey which are related to risk attitude in plausible ways. The survey measure also predicts individual behavior towards risk in other cases and even outperforms the experimental measure in this respect.
\end{abstract}




\section{Experimentally validated survey evidence on individual risk}

\section{attitudes in rural Thailand}

\section{Introduction}

Individual risk attitudes are a core determinant of economic behavior and have thus been under close scrutiny (e.g., Guiso and Paiella 2005; Tanaka, Camerer, and Nguyen 2010). Many experimental studies are now being conducted - in developing as well as developed countries - which provide comprehensive information about behavior towards risk (e.g., Eckel and Grossman 2008; Cardenas and Carpenter 2009). The shortcoming of this line of research, however, is that evidence is derived from smaller samples due to the efforts necessary in conducting experiments. These restricted samples hardly have enough variation (and scope) in their socio-economic variables to be useful in broader micro-econometric analysis. Thus, there is an urgent need to generate information about individual risk attitudes in a more simple way which can be applied in the increasingly popular large panel studies (see Dercon 2008).

We take the route of Dohmen et al. (2011) and test the validity of a simple survey item on risk attitude by a related field experiment. As in their benchmark study in Germany, we find for our sample of more than 900 respondents in rural Thailand, that a simple selfassessment of one's risk attitude - as part of a survey study - provides a useful measure. This self-assessed risk attitude indicates risk aversion of respondents on average, has appealing socio-demographic correlates (see Donkers, Melenberg, and Van Soest 2001) and is validated by an experiment with the same individuals. Reassuringly, the self-assessed risk attitude also predicts behavior in other cases of risk taking (see also Jaeger et al. 2010; or Dohmen and Falk 2011); e.g., in the purchase of lottery tickets, the survey item predicts behavior even better than the experimental measure. 
Our study is part of a larger research project which relies on a representative survey of rural households in three provinces of Northeast Thailand. In order to test the validity of simple questions about risk attitudes in a large scale survey, we compare answers with a standard risk experiment of the Holt and Laury (2002) type. This validation is essential as survey items are not incentive compatible and thus may yield accidental findings. The expected financial incentive for participation at the half hour experiment is more than a full day wage of a rural laborer. As we are addressing exactly the same individuals, we can directly compare more than 900 participants' responses for the survey item and for the experiment. We find that the survey item predicts the outcome of the experiment to a statistically significant degree. This relation is not disturbed by considering several further possible determinants of risk attitudes, such as age, gender etc. Thus a simple survey item giving the self-assessed risk aversion of an individual may be a useful measure. This result is in line with the related literature.

In order to check the reliability of our result we proceed in four steps: first, the selfassessed risk attitude is examined further by relating it to socio-demographic variables. These correlations - bivariate or multivariate - have largely conventional signs. Among income and other wealth-related variables, it is consumption that seems to capture best standard effects of economic status on risk attitude, possibly because it can be measured more accurately than other parameters in developing areas. Moreover, the influence of gender and height on selfassessed risk attitude is weak at best for our group. Although coefficients have the expected signs, they turn insignificant in most (multivariate) regressions.

Second, we further challenge the explanatory power of the general risk attitude survey measure for the experimental outcome in two ways: we exclude those respondents whose answers may be questionable, which does not affect our results. Then, we form three subgroups with different degrees of education and repeat the analysis. The explanatory power 
is better for respondents with longer years of schooling, indicating less noise in responses, but it is important for our purpose that the relation also holds for the least educated group with only four years of schooling.

Third, we take again the route of Dohmen et al. (2011) and examine whether the general risk attitude survey measure does predict other cases of behavior towards risk. Therefore, we make use of two survey items asking for risk-related behavior, i.e. the purchase of lottery tickets and the fact of being self-employed. Reassuringly, we find that the general risk attitude does predict behavior in these two cases of real world behavior.

Fourth, the relevance of the survey measure is supported by "horse-races" with the experimental measure in the two above mentioned cases of behavior towards risk as the survey measure has more explanatory power. This also tends to hold when we enlarge the comparison by a third measure of risk attitude, i.e. a survey item regarding a hypothetical investment lottery. This investment lottery addresses risk aversion in a financial environment and is thus different from the general risk aversion addressed in the standard survey item and the experiment.

Our study is related to various studies conducting experiments in developing countries with a focus on eliciting people's risk aversion, starting with Binswanger $(1980,1981)$ and being surveyed by Cardenas and Carpenter (2008). Our results are similar to the literature; so in this respect we add a new study with a comparatively large sample of more than 900 participants. Our study is of course also related to the increasingly popular (panel) survey studies, uncovering very broad aspects of people's lives in developing countries through a broad set of socio-demographic variables available.

Regarding its research design, our study is built on Dohmen et al. (2011). They are the first to validate survey evidence on risk aversion by an experiment. Their research is based on a large socio-economic panel in Germany. We deliberately rely on their survey items and 
experiment and apply it to a developing country. We differ in research design as they run the experiment and the linked survey with another group than the underlying socio-economic panel, although their experimental group is large (450 participants) and representative for the even larger survey group of the socio-economic panel. Moreover, due to the high income level in Germany, monetary incentives relative to income are higher in the poor Thai area. Tanaka et al. (2010) directly link survey and highly-incentivized experiments to the same persons, however, three years lie in between survey (2002) and experiment (2005). Moreover, they consider only few socio-economic control variables. Finally, there are two other recent studies building on Dohmen at al. (2011) which analyze, however, smaller student populations. Lönnqvist et al. (2010) compare the same 232 students' risk attitude elicited via selfassessment and via an incentivized laboratory experiment. Surprisingly, the two measures are not significantly related but the survey measure can predict other dimensions or risky behavior whereas the experimental measure cannot. Ding, Hartog, and Sun (2010) also compare survey and several experiments for 121 Chinese students and find among others that survey measure and experimental are correlated as expected. Overall, we contribute to this strand of literature since we integrated the experimental validation into a representative household survey in a developing country.

Our study is structured into four more sections. Section 2 describes our data, i.e. the survey sample and the experiment. Section 3 presents results of the self-assessment and Section 4 of the experiment. Section 5 examines the usefulness of the survey item for predicting behavior towards risk in further cases and Section 6 reports more robustness tests. Finally, Section 7 discusses findings and Section 8 concludes. 


\section{The survey sample}

Our study is based on a survey sample which is typical for the rural population in the Northeastern part of Thailand. This area is the poorest among the large five regional areas of Thailand.

The survey data was collected in 2008 as part of a larger research project on the measurement of vulnerability to poverty in rural Thailand. Therefore, we have focused on the less industrialized and relatively poor Northeastern region and picked three distinct provinces thereof. Within each of these three provinces the sample is representative for their rural areas, i.e. capital cities have been excluded. As the three provinces are weighted according to their population, the overall survey also provides more general information about the rural population in Northeastern Thailand. When it comes to personal information, however, the survey is biased towards household heads as they were the preferred survey participants.

The overall survey covers a sample of almost 2,200 households which has been drawn in a three stage sampling procedure. In the first stage sub-districts within a province were chosen with probability proportional to size (number of households) and implicit stratification by population density. From each sampled sub-district two villages were sampled with probability proportional to size. In the third stage, a systematic random sample of ten households was drawn from household lists of the rural census ordered by household size.

Questionnaire items cover a range of socio-demographic characteristics of rural households and respondents. Because of our goal to examine risk attitudes, respective items were included in the survey wave conducted during April and May 2008. In addition, an experiment for eliciting risk attitudes from the respective respondents was conducted in the largest of the three provinces, i.e. Ubon Ratchathani. It covers 950 of the 2,200 households. This provides our regular sample, for which we have the full questionnaire information plus the experimental results. 
Due to our focus on risk attitudes and their relation - among others - to financial variables such as income and wealth, we restrict our sample to answers from respondents to the age group of 18 to 80 years. It does not seem convincing to ask quite young or quite old people about financial affairs of the household. This reduces our sample by 16 people (whose inclusion does not change results qualitatively) so that we normally have a maximum of 934 responses.

\section{Self-assessment of risk attitude}

\subsection{Result of the self-assessment}

The self-assessed risk attitude by the Thai respondents (from our Ubon Ratchathani sample) is qualitatively the same as in other studies, regarding their tentative risk aversion and other characteristics of the response.

In order to elicit risk attitudes of our target population, we have adopted the general risk question from the German socio-economic panel, the so-called SOEP. The SOEP introduced in 2004 the following question: "Are you generally a person who is fully prepared to take risks or do you try to avoid taking risks?" Responses are given on an 11-point Likert scale where the value 0 means "not at all willing to take risks" and the value 10 means "very willing to take risks". It is intended that this self-assessment is very general and does not refer to any specific circumstances, such as financial affairs or financial lotteries.

The histogram of respondents' self-assessment is shown in Figure 1. The fact that the bars are slightly higher on the left of the diagram than the right could be a hint for some average risk-aversion within our sample. This interpretation is supported by a mean value of 4.56 which is slightly smaller than a middle value of 5.0. A second feature of this histogram is the high bar at its middle with about a $40 \%$ share of all responses. Whereas it is expected that a Likert scale generates many responses at its middle, the size of this effect is strong, 
compared for example to the German SOEP data with about 22\% (Dohmen et al., 2011). A third interesting feature in Figure 1 is the high response to the two extreme categories with about $12 \%$ each. The second and third features taken together seem to indicate that these Thai respondents are very decisive decision-makers.

Overall, the response is within the range of expectations. In the next step to examine the risk attitude of our sample, we analyze simple rank correlations between the self-assessment and variables that are potentially related to risk attitude.

\subsection{Correlates of the self-assessment}

The self-assessment of risk attitude in our sample is significantly correlated to a variety of variables, mostly in the expected way. Some signs, however, differ from studies in advanced countries and indicate that studies in developing countries deserve attention.

We derive variables of potential interest from earlier studies and allocate them into five groups. (1) First, we consider variables that are largely exogenous with respect to risk attitude. This refers to the sex and age of respondents, two variables that are widely covered in the literature. Findings tend towards women and older people being more risk averse (e.g., Donkers et al. 2001). If one would allow for further alternatives, there may be even riskseeking by older respondents on the assumption that prospect theory generates the decision (see Harrison, Humphrey, and Verschoor 2010). In addition, Dohmen et al. (2011) consider the height of respondents and find that taller persons tend to accept more risk (see Persico, Postlewaite, and Silverman 2004). This variable has the relatively smallest (and sometimes insignificant) impact. Despite their largely exogenous character, these three variables may be possibly and partially endogenous because gender, age, and height are related to economic status and thus to risk taking. To put it differently, it may be crucial to also control for economic status. 
(2) It is known from many experiments and it can be expected from theory that the economic status will impact risk attitude. Accordingly, higher income and higher wealth will tentatively go along with less risk aversion (e.g., Donkers et al. 2001). We add consumption because the measurement and interpretation of income is subject to difficulties in developing countries. Finally, as human capital is an important determinant of economic status we include the years of education that the adults in our sample have experienced. (3) Some studies find that family status is related to risk attitude. Married respondents with larger families, i.e. usually having more dependents, tend to be more risk averse (e.g., Dohmen et al. 2011). (4) As next group of variables we consider respondents' employment status. It has often been found that self-employed people are less risk averse, the opposite is expected to apply to unemployed and civil servants (e.g., Cramer et al. 2002; Caliendo, Fossen, and Kritikos 2009). (5) Finally, we consider other subjective attitudes. People who say that they feel less healthy tend to be more risk averse, whereas people with more optimistic expectations with regard to their living conditions are expected to be less risk averse (see e.g., Dohmen et al. 2011).

The full list of variables which we consider is given in Table 1. The relevant items of the questionnaire are described at the table's bottom. Column (1) gives the number of observations which is consistently above 930, with the exception of income, where about 20 cases are missing. Column (2) presents the variable's mean, column (3) the respective standard deviation.

In addition to these descriptive statistics column (4) gives the coefficient of the Spearman rank correlation between the variable and the item of general risk attitude introduced above (see Figure 1); the p-value is given in parenthesis. It is obvious at first sight that many of these coefficients are statistically significant. Moreover, many of these coefficients have the expected sign, among them the three largely exogenous variables. We find indeed that female, older and shorter respondents all show more risk averse attitudes. 
Regarding economic status variables, results fit with expectations as well; consumption and education have significant signs, whereas coefficients on income and wealth are not significant. Regarding the family status, variables provide some surprise because "being married" and "living in a larger household" do not go along with higher risk aversion and only the variable "having more dependents" has the expected significant relation towards higher risk aversion. However, Miyata (2003) found that "co-residence", i.e. in our case "being married" and "living in a larger household," goes along with lower risk aversion and interprets this as a security blanket. Regarding the employment status, both coefficients, on selfemployment and unemployment, meet the expectation, whereas "being a civil servant" has an unexpected positive sign, indicating risk acceptance, although at a p-level of $15 \%$ only. Finally, subjective attitudes have the expected (significant) signs.

Overall, correlates mainly suggest the conventional structure in our sample. Interestingly, with respect to being a civil servant, being married and living in larger households - these characteristics are not correlated with more risk aversion, although evidence from advanced countries shows this relation. An explanation could be that these variables have a different meaning depending on living circumstances. In a developing country, for example, civil servants, married respondents, and those in larger households can afford accepting more risk than others. Before interpreting these correlations even further, possible relations will be tested in a multivariate approach (Hill, 2009).

\subsection{Multivariate correlates of the self-assessment}

The multivariate interval regressions confirm our earlier findings on correlates, although coefficients on several variables become insignificant.

Regarding the estimation approach, we follow Dohmen et al. (2011) and take an interval regression approach whenever possible because the marginal categories may be understood as 
open intervals. Alternatively, ordered probit regressions and OLS regressions lead to similar results as we will demonstrate in exemplary form later on. The complex sample design seems more important by correcting standard errors for clustering and unequal sample weights (see Wooldridge 2002, 134f.). Our data stem from a sample with villages as clusters and 10 households per village as the ultimate sampling units. In few cases, this procedure cannot be fully applied because grouping or exclusion of observations lead to clusters with single observations (we report this in table notes).

As a first specification we only consider the three largely exogenous variables so that causality does not seem to be a major issue. The result in Table 2, column (1) shows, that signs are the same as for the correlates but only age has a significant coefficient. The insignificant gender coefficient may require further consideration as several studies, such as Harrison, Lau, and Rutström (2007) or Dohmen et al. (2011), find a negative statistically significant coefficient. However, Eckel and Grossman (2008) comment on this result with the qualification that "... there is enough counter-evidence to warrant caution". They criticize, in particular, a lack of crucial controls, an issue where our data allow quite some adequate coverage.

As a second specification we also consider variables for economic status. If we include them one by one in order to account for their correlation to each other, wealth (in logarithmic form) has a p-value of $10 \%$, income (also in logs) has a p-value of $5 \%$ and comparatively best is consumption (in logs) with a p-value of $2 \%$. Therefore we only present this last result in column (2). Here, and for some further socio-demographic variables, we are aware that causality is less clear as, for example, the willingness to take risk may impact the economic status. We are not aware of a good instrument, however, so that we report correlations in this case between risk attitude and variables instead of determinants of risk attitude. 
As our last specification we include all variables being considered so far in one regression. The result in column (3) shows that signs are basically as expected but that only age stays significant, consumption loses significance and self-employment as well as optimistic expectations turn significant. These findings are quite robust in that significant variables keep significance even with some modified specifications, whereas the gender variable has a positive coefficient here but is insignificant (and never becomes significant with a positive coefficient). Note that the qualitative result is unaffected by employing an ordered probit regression or an OLS regression as shown in column (4) and column (5), respectively.

In summary, the self-assessed risk attitude has intuitive correlates which tend to hold in a multivariate regression as well. This is our basis to introduce the experiment.

\section{$4 \quad$ Experiment on risk attitude}

In addition to the self-assessment, an experimental elicitation of risk preferences was conducted among the sample from Ubon Ratchathani province. We describe the standard experiment in Section 4.1, then we test in Section 4.2 whether the self-assessed risk attitude provides useful information in explaining the experimental result and show some robustness considerations in Section 4.3.

\subsection{The experiment}

Upon completion of the survey questionnaire, the respondent was asked to participate in a risk experiment which is designed as in Dohmen et al. (2005). This experiment is of the established Holt and Laury (2002) type. The exact experimental design, including the presentation to participants, was decided after several tests run in order to ensure appropriateness. The interviewers conducting this experiment received an intensive training ensuring uniform treatment in the field. Indeed, the ex post evaluation does not reveal any 
significant differences in results between interviewers. In order to reduce possible distortion from spillovers between the survey item and the experiment, the latter two are presented at different time: the survey item somewhere in the middle of the household survey and the experiment after finishing the survey. Nevertheless, there is still the possibility of a kind of "forced correlation" which we can partially address in the robustness Section 4.3.

In the experiment, the respondent was confronted with 20 choices between a safe payoff and a lottery. These choices are presented on a table showing 20 rows. At each row the participant was asked in ascending order of the rows whether she would prefer to receive the increasingly higher safe payoff or to play a lottery where the payoff could be either zero or 300 Thai Baht, corresponding to about 17.46 US-dollars at purchasing power parity or well above a full day salary. This financial incentive should be large enough to address any respective concerns (Camerer and Hogarth 1999; Holt and Laury 2002). The participant was also informed in advance that after the 20 choices had been noted, a random number between 1 and 20 would determine which of the 20 choices was to be played with real payoffs. A preference for lower row numbers implies higher risk aversion, a safe payoff at 150 Baht versus the zero or 300 Baht lottery (row 16) implies risk neutrality, whereas preferring the lottery at rows 17 to 20 corresponds to risk loving behavior. The row in which the respondent's preference switched from the lottery to the safe amount was marked. This "switching row" informs about the person's risk attitude.

After the choice had been noted, a number between 1 and 20 was drawn randomly. In case the number drawn was below the respondent's switch point, the lottery would be played by tossing a coin and 300 THB would be paid upon "King" and 0 otherwise. If the random number was higher than the switch point, the respondent received the safe amount. By this procedure, the incentive to reveal actual preferences was ensured. The cash payment to 
everyone is different from Dohmen et al. $(2005,2011)$ where the game was played with real money with a probability of $1 / 7$ and the money was transferred by cheque.

The result of the experiment is shown in Table 3. Column (1) gives the share of answers in the respective row and column (2) gives the cumulative shares. We see that participants in the experiment behave quite risk averse, a finding that has been stated for Ethiopia too (Yesuf and Bluffstone 2007) and which corresponds to the high incentives (Holt and Laury 2002). The share of risk-neutral and risk-loving respondents is $10 \%$ and thus smaller than in Holt and Laury (2002) with 19\% and in Dohmen et al. (2011) with 13\%. Looking at details, however, the tendency to answer at the extremes resembles the response to the self-assessed risk attitude. There are 40 participants who rather reject to play the experiment as they do not want any money. Many of them explained that they never play any lotteries, which according to casual observation may be related to the misuse of lotteries by sales people. Then there are another 234, i.e. about a quarter of participants, who prefer a safe 10 Baht to anything else. At the other extreme there is a comparatively large group of 75 participants, i.e. about $8 \%$, who choose row 20, i.e. who are risk-loving by preferring a lottery to all safe alternatives even though the expected value of the lottery is clearly smaller than the expected value of the riskless alternative.

As a last step we transform the experimental results for each row into simple conventional coefficients of risk aversion. For convenience, we assume a utility function with constant relative risk aversion $r$ as given by equation (1), intervals for the coefficient of relative risk aversion implied by the switch point between lottery and certain amount can be calculated if initial wealth is assumed to be 0 .

$$
u(w)=\frac{w^{1-r}}{1-r}
$$


The coefficients of partial risk aversion are reported in column (3) of Table 3. The median switch-point at 40 Baht implies that half of the population exhibits a coefficient of relative risk aversion above 0.6

\subsection{Experiment and self-assessment}

As the experiment shows some risk aversion of respondents on average and the selfassessment allows for this possibility too, we are now interested to know whether these two measures are related. Therefore, we show a graphical exposition of this relation and then examine whether the self-assessment is a good proxy for the experiment and can thus predict the experimental outcome.

In order to present the relation between the self-assessment and the experimental measure Figure 2 shows for the 11 categories of the survey item (between 0 and 10), the respective mean of responses in the experiment, i.e. the mean choice of the "switching row" (between 1 and 20). Moreover, to indicate the variation of answers, we also give the range for the standard deviation around the mean value. The figure shows that there is indeed a clear positive relation between both measures of risk attitude but that there is also a lot of variation in responses. Thus we proceed in analyzing this relation.

In order to test the hypothesis whether the self-assessment is a good predictor for the experiment we estimate various models in which the experimental outcome, i.e. the choice of a "switching row", is to be explained by the same person's self-assessment. Results presented in $\underline{\text { Table } 4}$ are very similar to Dohmen et al. (2011) and indicate that these examinations can be applied in poor developing areas too.

Column (1) gives the simplest specification, i.e. an interval regression where just the two mentioned variables are related to each other plus a constant. Obviously, the coefficient on the self-assessment is positive and highly significant. It is also of some economic importance as a 
change by one unit in the self-assessment goes along with a change in the experiment by almost 0.3 rows. In order to test the robustness of this relation and to control whether the exogenous determinants of the self-assessment have an independent meaning for the experiment, see column (2). The coefficient on the self-assessment is hardly different and the control variables are all insignificant. The result is qualitatively unchanged by including further variables. We just present the specification when all control variables are used (see column 3) but the size and significance of the "general willingness to take risk" variable is basically unaffected by the particular specification. This also extends to ordered probit or OLS regressions. Thus, we do not care further about possible multicollinearity between explanatory variables in certain specifications (which is also justified by low variance inflation factors for respective OLS regressions).

Despite their obvious empirical relation, the survey item and the experimental measure of risk attitude do not necessarily measure the same thing. Whereas the experimental measure has been established and is used in this sense as revealing an innate preference for risk aversion, the same cannot be said with confidence for the survey item. It seems well possible that the survey item also captures an individual's ability to take risk as the question is about being "prepared to take risk". If this is the case, the survey item may be better in predicting real world behavior towards risk and still the experimental measure may be better in revealing an innate risk aversion.

\subsection{Robustness considerations}

Despite the robustness of this finding regarding the inclusion of several sociodemographic variables (see Section 4.2), we apply four more robustness tests. These additional tests address concerns that the high degree of variation in responses and thus the relatively low explanatory power of the above regressions might mask more severe distortions. 
As a first possible distortion we examine the impact of those respondents who violate the basic assumption of monotonicity. Thus we exclude those 40 persons from our sample who choose row 1 in the experiment (see Table 3), i.e. who did not even take the safe amount of 10 Baht without any risk by choosing row 2 . These respondents may be regarded as making a mistake as their preference most probably violates monotonicity and thus a very basic assumption of any theory on human decision making. If we speculate that these persons did not understand the experiment one should exclude them from the sample. Reassuringly, doing so does not affect our qualitative result (available on request).

As a second possible distortion we re-examine regressions by excluding those respondents who may reveal by their response that they do not really understand the survey item on risk attitude. A possible reaction to a lack of understanding may be the choice of answering category 5 , i.e. positioning oneself half way between the extremes. This concern is in particular nurtured by the fact that about 40 percent of respondents were choosing this category (see Figure 1) and thus more than in comparable surveys. The regression based on the largely reduced sample is given as specification (1) in Table 5. The result is qualitatively unchanged. Independent from this finding, the fact that 40 percent of respondents chose just one out of 11 categories is a concern by itself. It implies that variations of response are very low which limits the use of this survey item for analytical purposes and thus in the last instance, possibly also for policy purposes.

As a third possible distortion we address the possibility that responses may feel forced to respond in a similar pattern in both exercises. This may distort the responses in particular if it coincides with misunderstanding (see test 2 above). Thus, we exclude those respondents who choose the middle category 5 in the survey or the middle category 10 in the experiment. Again, the regression result in specification (2) of Table 5 is qualitatively unchanged compared to the benchmark specification in Table 4. This also applies to further sample 
definitions, such as exercises with samples where the middle category in the experiment is defined broader than just category 10 (available on request).

As a fourth possible distortion, we address the problem of comprehension from another perspective. One may expect that the survey question or the experiment could be difficult to understand for the less educated. Accordingly, we split the total sample into three groups: a first group with up to 4 years of schooling (which was the minimum years of schooling until the 1980s) which encompasses 597 participants, i.e. more than $60 \%$. The next group has 5 or 6 years of schooling reflecting the increase of minimum school years to 6; this group has 167 members. So, the remaining group with more school years than 6 includes 164 members. We again run the same regressions as reported in Table 4 separately for these three groups. Results in Table 5 (specifications 3 to 5) show indeed that the coefficient of interest increases with better education from 0.26 over 0.30 to 0.38 . This indicates that longer education supports the matching between experiment and self-assessment, which may be caused by better understanding (and thus less noisy answers) or by a better anticipation of consistency checks done by researchers (see also Benjamin, Brown, and Shapiro 2005; Dohmen et al. 2010). However, more important for our purpose is the fact that the main relation also holds for the least educated so that the overall result is not driven by any of these subgroups. Accordingly, the finding holds qualitatively when using interaction terms of the survey item on risk attitude and educational groups (indicating no significant differences between groups) or when using different groupings of school years.

In this section we have always treated the relation between experiment and survey but not these two elements separately. One might speculate whether either survey or experiment may be more difficult to understand and might thus yield more distorted results in general or for the less educated in particular. Ex ante, it may appear that the experiment is more subject to distortions because it seems to be a more complicated exercise compared to answering a 
simple question. However, respondents get introduced into the experiment in quite some detail and the execution is simple as they always decide between two obvious alternatives, whereas the survey item refers to an unspecified situation. One can easily imagine that an answer to such an abstract survey question may challenge the understanding of many individuals. In the end we prefer not to speculate whether distortions refer more to survey or experiment but emphasize that the four above documented robustness tests all indicate that the relation between survey and experiment is robust to variations of the sample.

In summary, we find for our sample in rural Thailand that the outcome of the incentivized experiment on risk attitude can be explained by the survey item on risk attitude. This is consistent with Dohmen et al. (2011) who pioneered this kind of research with a sample taken in Germany. The following section provides tests whether the survey item is also useful in explaining further implicit statements on individual risk attitude.

\section{$5 \quad$ Evidence on individual risk attitude in other cases}

Evidence provided in this section shows that the survey item on general risk attitude is also useful in predicting individual behavior towards risk in other cases. First, we introduce a third measure of risk attitude, i.e. the response to a hypothetical investment lottery, and relate the three risk measures to each other (Section 5.1). Then we examine the predictive power of the survey item on general risk attitude in cases of revealed behavior towards risk, i.e. regarding buying lottery tickets (Section 5.2) and being self-employed (Section 5.3). In these cases, the survey measure has clearly more predictive power than the experimental measure and it is also superior to the hypothetical lottery measure. 


\subsection{Response to a hypothetical investment lottery}

The survey contains a lottery question on respondents' decision about a hypothetical investment (see Dohmen et al. 2005). The scenario is as follows: "Imagine you had just won 100,000 Baht in a lottery and you can invest this money in a business. It is equally likely that the business goes well or not. If it goes well you can double the amount invested after one year. If it does not go well you will lose half the amount you invested. What fraction of the 100,000 Baht would you invest in the business?" This lottery is less abstract than the other risk items and thus may be more appealing to some participants. Another intended difference is its clear reference to a financial issue and thus its specificity compared to a general risk item which might influence responses by women as argued by Schubert et al. (1999; see also Eckel and Grossman 2008).

The distribution of responses is shown in Figure 3. Obviously, this figure very much resembles the earlier Figure 1 on the response to the general willingness to take risk. Again, we get a high outcome at the middle category which is here even close to 50 percent and again respondents tend slightly towards a share of less than 50 percent being invested in the risky asset, indicating some risk aversion on average.

Thus we take the amount invested in the risky asset in this hypothetical investment lottery as our third measure of risk attitude. The rank correlations between these three measures show the expected result, i.e. a statistically highly significant positive correlation (see Table 6). The degree of correlation is highest between the survey item and the hypothetical lottery and the correlation is weakest between the experiment and the hypothetical lottery. The correlations remain robust if we reduce the sample by excluding persons who choose middle categories. The respective coefficients of correlation are shown in Table 6 as (a) for the full sample, (b) for a sample excluding those about 40 percent persons 
responding with category 5 in the survey item and finally (c) excluding all persons who choose a middle category in any of the three risk measures.

\subsection{Results on buying lottery tickets}

In this section we examine whether the general risk attitude can explain revealed behavior, i.e. whether a household member buys lottery tickets. The incidence is about $50 \%$. We test whether the general risk attitude can predict this decision and how well the survey measure succeeds in comparison to the experimental measure and to the hypothetical investment lottery measure.

We analyze the question whether any member of the household had in fact purchased lottery tickets during the last 12 months, i.e. we want to explain a binary variable. Table 7 presents respective regressions in an ordering of columns where we start explaining the purchase of lottery tickets without any measure of risk attitude and then proceed by including more and more risk measures. That is column (1) shows the contribution of all sociodemographic variables in explaining the purchase of lottery tickets with the expectedly signed significant coefficients on gender, age, height and consumption. Extending this the next column (2) also relies on the survey-based general risk attitude. Column (3) gives the specification result with including only the experimental measure and column (4) shows the inclusion of survey item and experiment. Obviously, the explanatory power of the survey item is relatively stronger as the coefficient on the experiment-based measure becomes insignificant.

When we turn to the hypothetical investment lottery measure being considered in columns (5) and (6), we see again that it has some explanatory power, although the $\mathrm{R}^{2}$ of this specification (column 5) remains lower than for the survey item regression (column 2). When the survey and the hypothetical investment lottery measure are considered contemporaneously, 
the coefficient of the latter loses significance, also indicating that the survey item has more predictive power (column 6). This result remains stable when we run the horse race with all three risk measures in a single regression (column 7), because the experimental measure again drops out and the survey item is relatively most important.

We realize that the explanatory power of all these specifications is rather low as indicated by the respective $\mathrm{R}^{2}$. One reason for this is our blurred matching between personal characteristics and the fact that the purchase of lottery tickets cannot be related to a certain person but to a household only. Another reason may be omitted variables, such as parents' risk attitudes (Dohmen et al. 2011).

Finally, we may also face some endogeneity problem in the sense that people like to purchase lottery tickets which may influence their behavior towards our risk measures. For example, regarding the experiment they may assume to play another game, just like participating at a lottery.

\subsection{Results on being self-employed}

Finally, we examine the fact whether the respondent is self-employed apart from farming. The incidence is $12 \%$ for self-employment. We test again the predictive role of the survey-based general risk attitude, the experimental measure, and the hypothetical investment lottery measure.

The respective Table 8 has the same ordering of columns as Table 7. As one may expect for a risky decision, the significant signs indicate more risk aversion for older people and people with lower consumption levels. Being married is also related to not being selfemployed, which is the finding from advanced economies.

Regarding the importance of the three risk measures in explaining the fact of being selfemployed, we find a similar pattern as before. The survey-based measure of the general risk 
attitude predicts the fact of being self-employed in the expected way, whereas the experimental measure does not. The hypothetical investment lottery-measure is again useful and equally good as the survey item.

The overall explanatory power of these regressions is better than in the case before, i.e. explaining the purchase of lottery tickets. Nevertheless, we again miss potential variables. A particular influence in the case here may stem from factors that enforce persons to become self-employed who in fact never wanted to be self-employed. Such situations may result from unexpected loss of income from regular sources, or from (changes in) preferences which are not covered by our survey.

\section{Further robustness examinations}

This section shortly reports more robustness examinations in four directions: first, we report findings on further variations of our core regressions by leaving out the 40 respondents with inefficient choices in the experiment, by dropping the potentially endogenous selfemployment variable and by reducing regressors to significant ones. In all cases, results do not change qualitatively (results are available on request).

Second, we use the full sample from all three provinces in Northeast Thailand that are covered by the survey. However, the experiment was only conducted in one, albeit the largest among the three provinces, so that the comparison with a larger sample than reported in the tables above is incomplete. Moreover, there is no difference with respect to the survey-based risk measure even though some other variables may turn (in)significant due to the extension of the sample (results are available on request).

Third, we modify the approach explaining the purchase of lottery tickets (Section 5.2). In order to consider the fact that respondents may not be responsible for the decision under review here, we reduce our sample to those respondents who are household heads. This may 
improve precision at the cost of reducing the sample size. The outcome is still qualitatively the same as Appendix 1 shows and rather sharpens the difference between the two measures of risk attitude when compared to Table 7: the coefficients of the survey measure becomes slightly bigger and of the experimental measure slightly smaller.

Fourth, we have repeated all examinations including the experimental measure but with a different definition of this measure. Instead of just taking the number of the switching row (from 1 to 20) as an indicator of less risk-averse behavior, we now take the respective coefficient of relative risk aversion. In order to make results easier comparable, we multiply it by minus one. Appendix 2 reproduces former Table 4 and Appendix 3 shows the former columns (4) from Tables 7 and 8, respectively. The role of the experimental measure does not change, independent of its exact definition.

Overall, major findings are unaffected by these robustness examinations.

\section{Discussion}

The use of survey-based measures of risk attitudes does not seem to be fully convincing ex ante. On the contrary, economists invest great effort in designing and conducting incentivecompatible experiments in order to reveal behavior, even though experiments do not need to be superior for all purposes (e.g., Handa and Maluccio 2010). Therefore, one needs good reasons to use a survey measure instead of an experimental measure.

An argument supporting it is its practicality. Risk aversion is an important ingredient of real-world behavior and people are very heterogeneous in their degree of risk aversion at an individual level (Donkers et al. 2001). Individual behavior is often studied with the help of large panel data sets that are generated with enormous effort. So, it is tempting to include a simple item referring to risk attitude which would be easy to implement. However, researchers 
doubt the reliability of a survey-based measure so that there may be a trade-off between data availability and data precision.

In order to address the empirical relevance of this possible trade-off Dohmen et al. (2011) conduct an experiment testing the validity of the survey evidence. They find that the survey measure is a good proxy for the experimental measure. We take their route with one important difference, i.e. we conduct the experiment with the same persons as the underlying large household survey. This provides socio-demographic information on the experimental subjects (as in Tanaka et al. 2010), may improve precision, and also opens the possibility for a various direct comparisons between both measures. In independent work, Lönnqvist et al. (2010) also exercise the direct comparison between both measures on a sample of 232 students: they do not find a positive correlation between the two measures, different from Dohmen et al. (2011) and our study. Moreover, they find that only the survey measure is related to personality measures, indicating that the survey measure may be even more reliable than the experimental measure - a finding that is qualitatively like ours, despite their completely different research design. The resulting cautious optimism on the survey measure is also supported by more general findings on subjective expectation statements in developing countries as people understand probability concepts and give reliable responses (Delavande, Giné, and McKenzie 2011). However, there are also studies finding that respondents have trouble with stating reliable probability assessments (e.g., Harrison et al. 2010).

Our research design is conservative by relying on the procedures of Dohmen et al. (2011) so that wording of the survey items and the experiment design is identical. Thus, our findings can be directly related to other studies also relying on Dohmen et al. (2011), including Jaeger et al. (2010), Ding et al. (2010), Lönnqvist et al. (2010), and Dohmen and Falk (2011). All these studies indicate some usefulness of the survey measure, although in very different ways. 
Our study is unique in conducting the experiment with the respondents of a representative household survey in a developing country at the same time. If the outcome of this line of studies could be generalized - over regions, times or other variations - it might be very helpful for research based on large household panel data sets because individual risk attitudes can be approximated by a simple survey-based item. However, further research seems necessary to examine survey-experiment-relations. Any practical implementation would need more information whether the extension to other segments of the population (urban households) or countries provides robust results. It would be important to know, to which degree the response to the survey item may depend on the respondents' ability to take risk (which may be different from the same person's innate preference to take risk). Finally, one would like to know whether the very simple survey measure used here can be extended to more complex concepts of risk attitude as recently analyzed in developing countries for example by Yesuf and Bluffstone (2009), Harrison et al. (2010), or Tanaka et al. (2010).

\section{Conclusions}

This is the first study examining the merit of a survey based measure of individual risk attitude by way of a representative survey being directly linked to an experiment in a developing country. We confirm the Dohmen et al. (2011) finding for a German sample that the simple self-assessment of risk attitude is validated by a highly incentivized experiment, here within the identical sample of more than 900 participants. The general risk attitude significantly predicts behavior in the experiment and this fit is not improved much in our sample by considering further determinants, such as age, gender, income and others. This finding is corroborated by the fact that the self-assessed risk attitude has meaningful and plausible correlates. 
We also find that the survey measure predicts behavior towards risk in two further cases: (1) it predicts the purchase of lottery tickets and (2) it predicts the fact of being self-employed. Interestingly, the experimental measure succeeds less in the same examinations. If we compare the survey and the experimental in a kind of "horse-races" the survey measure dominates. The findings hold when we add a third measure of risk attitude. This indicates that a simple survey-based measure may provide useful evidence on risk attitude, being particularly appealing for developing country research. 


\section{References}

Benjamin, Daniel, Sebastian Brown, and Jesse Shapiro. 2005. "Who Is 'Behavioral'?

Cognitive Ability and Anomalous Preferences.” Working paper, Harvard University.

Binswanger, Hans P. 1980. “Attitudes toward Risk: Experimental Measurement in Rural India." American Journal of Agricultural Economics 63:395-407.

Binswanger, Hans P. 1981. “Attitudes towards Risk: Theoretical Implications of an Experiment in Rural India.” Economic Journal 91:867-90.

Caliendo, Marco, Frank M. Fossen, and Alexander S. Kritikos. 2009. "Risk Attitudes of Nascent Entrepreneurs - New Evidence from an Experimentally Validated Survey.” Small Business Economics 32:153-67.

Camerer, Colin F., and Robin M. Hogarth. 1999. "The Effects of Financial Incentives in Experiments: A Review and Capital-Labor-Production Framework." Journal of Risk and Uncertainty 19:7-42.

Cardenas, Juan Camillo, and Jeffrey Carpenter. 2008. “Behavioural Development Economics: Lessons from Field Labs in the Developing World.” Journal of Development Studies 44:311-38.

Cramer, J.S., J. Hartog, N. Jonker, and C.M. Van Praag. 2002. "Low Risk Aversion Encourages the Choice for Entrepreneurship: An Empirical Test of a Truism.” Journal of Economic Behavior and Organization 48:29-36.

Delavande, Adeline, Xavier Giné, and David McKenzie. 2011. “Measuring Subjective Expectations in Developing Countries: A Critical Review and New Evidence.” Journal of Development Economics 94:151-63.

Dercon, Stefan. 2008. "Fate and Fear: Risk and Its Consequences in Africa." Journal of African Economics 17: ii97-127. 
Ding, Xiaohao, Joop Hartog, and Yuze Sun. 2010. “Can We Measure Individual Risk Attitudes in a Survey?" IZA Discussion Paper 4807.

Dohmen, Thomas, and Armin Falk. 2011. "Performance Pay and Multi-dimensional Sorting Productivity, Preferences and Gender. American Economic Review 101:556-90.

Dohmen, Thomas, Armin Falk, David Huffman, and Uwe Sunde. 2010. “Are Risk Aversion and Impatience Related to Cognitive Ability?" American Economic Review 100:123860.

Dohmen, Thomas, Armin Falk, David Huffmann, Uwe Sunde, Jürgen Schupp, and Gert G. Wagner. 2005. “Individual Risk Attitudes: New Evidence from a Large, Representative, Experimentally-validated Survey.” DIW Discussion Papers 511, Berlin.

Dohmen, Thomas, Armin Falk, David Huffmann, Uwe Sunde, Jürgen Schupp, and Gert G. Wagner. 2011. "Individual Risk Attitudes: Measurement, Determinants and Behavioral Consequences." Journal of the European Economic Association 9:522-50.

Donkers, Bas, Bertrand Melenberg, and Arthur Van Soest. 2001. "Estimating Risk Attitudes Using Lotteries: A Large Sample Approach.” Journal of Risk and Uncertainty 22:16595.

Eckel, Catherine C., and Philip J. Grossman. 2008. "Men, Women and Risk Aversion: Experimental Evidence.” In Handbook of Experimental Results, ed. Charles Plott and Vernon Smith. New York: Elsevier, forthcoming.

Guiso, Luigi, and Monica Paiella. 2005. “The Role of Risk Aversion in Predicting Individual Behavior.” Banca d'Italia Discussion Paper No.546.

Handa, Sudhanshu, and John A. Maluccio. 2010. "Matching the Gold Standard: Comparing Experimental and Nonexperimental Evaluation Techniques for a Geographically Targeted Program.” Economic Development and Cultural Change 58:415-47. 
Harrison, Glenn W., Steven J. Humphrey, and Arjan Verschoor. 2010. “Choice under Uncertainty in Developing Countries.” Economic Journal 120:80-104.

Harrison, Glenn W., Morten I. Lau, and E. Elisabet Rutström. 2007. “Estimating Risk Attitudes in Denmark: A Field Experiment.” Scandinavian Journal of Economics 109:341-68.

Hill, Ruth Vargas. 2009. “Using Stated Preferences and Beliefs to Identify the Impact of Risk on Poor Households.” Journal of Development Studies 45(2):151-71.

Holt, Charles A., and Susan K. Laury. 2002. "Risk Aversion and Incentive Effects." American Economic Review 92:1644-55.

Jaeger, David A., Holger Bonin, Thomas Dohmen, Armin Falk, David Huffmann, and Uwe Sunde. 2010. Direct Evidence on Risk Attitudes and Migration. Review of Economics and Statistics 92:684-9.

Lönnqvist, Jan-Erik, Markku Verkasalo, Gari Walkowitz, and Philipp C. Wichardt. 2010. "Measuring Individual Risk Attitudes in the Lab: Task or Ask? An Empirical Comparison.” Working paper, University of Bonn.

Miyata, Sachiko. 2003. “Household's Risk Attitudes in Indonesian Villages.” Applied Economics 35:573-83.

Persico, Nicola, Andrew Postlewaite, and Dan Silverman. 2004. "The Effect of Adolescent Experience on Labor Market Outcomes: The Case of Height.” Journal of Political Economy 112:1019-53.

Schubert, Renate, Martin Brown, Matthias Gysler, and Hans Wolfgang Brachinger. 1999. “Financial Decision-Making: Are Women Really more Risk-averse?” American Economic Review Papers and Proceedings 89:381-5. 
Tanaka, Tomomi, Colin F. Camerer, and Quang Nguyen. 2010. "Risk and Time Preferences: Linking Experimental and Household Survey Data from Vietnam.” American Economic Review 100:557-71.

Wooldridge, Jeffrey. 2002. Econometric Analysis of Cross section and Panel Data. Cambridge, MA: MIT Press.

Yesuf, Mahmud, and Randall A. Bluffstone. 2009. "Risk Aversion in Low Income Countries Experimental Evidence from Ethiopia." American Journal of Agricultural Economics 91:1022-37. 


\begin{tabular}{|c|c|c|c|c|c|}
\hline & \multirow{2}{*}{$\begin{array}{l}\text { No. } \\
\text { Obs. } \\
\text { (1) }\end{array}$} & \multirow[b]{2}{*}{$\begin{array}{l}\text { Mean } \\
(2)\end{array}$} & \multirow[b]{2}{*}{$\begin{array}{l}\text { Std. Dev. } \\
\text { (3) }\end{array}$} & \multicolumn{2}{|c|}{$\begin{array}{c}\text { Spearman rank } \\
\text { correlation }\end{array}$} \\
\hline & & & & Coeff. & (p-value) \\
\hline General willingness to take risk (WTR) & 933 & 4.556 & 2.945 & 1 & \\
\hline Switching row in experiment & 930 & 6.797 & 5.533 & $* * * 0.090$ & $(0.006)$ \\
\hline Negative of coefficient of RRA & 930 & -0.470 & 0.489 & $* * * 0.090$ & $(0.006)$ \\
\hline Amount invested in risky asset (10.000 THB) & 933 & 4.508 & 2.666 & $* * * 0.407$ & $(0.000)$ \\
\hline Female & 934 & 0.566 & 0.496 & -0.010 & $(0.763)$ \\
\hline Age (years) & 934 & 50.75 & 12.604 & $* * *_{-} 0.171$ & $(0.000)$ \\
\hline Height $(\mathrm{cm})$ & 933 & 158.26 & 7.722 & $* * 0.074$ & $(0.024)$ \\
\hline Log. consumption (\$PPP per AE) & 933 & 1.600 & 0.620 & $* * * 0.099$ & $(0.002)$ \\
\hline Log. income (\$PPP per AE) & 912 & 1.625 & 1.018 & $* 0.055$ & $(0.100)$ \\
\hline Log. wealth (\$PPP per adult) & 934 & 9.506 & 0.996 & 0.029 & $(0.371)$ \\
\hline Education (years) & 934 & 5.708 & 3.443 & $* * * 0.146$ & $(0.000)$ \\
\hline Married & 934 & 0.827 & 0.379 & 0.041 & $(0.208)$ \\
\hline Dependency ratio & 934 & 0.676 & 0.681 & $* * *_{-} 0.086$ & $(0.009)$ \\
\hline Household size & 934 & 4.105 & 1.836 & 0.022 & $(0.496)$ \\
\hline Self-employed & 934 & 0.117 & 0.321 & $* * * 0.115$ & $(0.000)$ \\
\hline Unemployed & 934 & 0.045 & 0.207 & $* *-0.076$ & $(0.020)$ \\
\hline Civil servant & 934 & 0.035 & 0.185 & 0.048 & $(0.145)$ \\
\hline Subjective health impairment & 933 & 0.159 & 0.366 & $*_{-} 0.060$ & $(0.067)$ \\
\hline Optimism & 931 & 0.314 & 0.841 & $* * * 0.120$ & $(0.000)$ \\
\hline
\end{tabular}

\section{Notes:}

General willingness to take risk is measured on an 11-point Likert scale ranging from 0 (unwilling to take risk) to 10 (fully prepared to take risk). Switching row in experiment refers to the row number of the lottery at which the subject's preference changes from the lottery to the safe amount. Alternatively, the experimental result can be described by intervals for the coefficient of relative risk aversion (RRA) assuming zero initial wealth. We use a negative transform of the interval midpoints in order to consistently represent increasing willingness to take risks with increasing values. Height is body height as reported by the respondent. Log consumption refers to the natural logarithm of household consumption per day divided by $\mathrm{OECD}$ adult equivalents $\mathrm{AE}(\mathrm{AE}=1+0.7 *$ (adults- 1$)+0.5^{*}$ children), $\log$ income is calculated analogously, whereas log wealth refers to household wealth divided by the number of adults (i.e. persons aged $>=15$ ). The dependency ratio is the number of resident household members below 15 or above 64 years divided by the number of household members between 15 and 64 years of age. Household size is the headcount of persons living in the household for at least half of the reference period. Subjective health impairment takes the value of 1 if the respondent considers herself to be sick and zero otherwise. Optimism is proxied by the question on expectations for well-being after one year's time and takes values from -2 (much worse) to +2 (much better).

Spearman rank correlation coefficients and respective p-value are reported for the general willingness to take risk paired with all other variables. 
Table 2: Multivariate correlates of the self-assessment of general risk attitude

\begin{tabular}{|c|c|c|c|c|c|}
\hline & $(1)$ & $(2)$ & (3) & $(4)$ & $(5)$ \\
\hline Female & $\begin{array}{l}-0.023 \\
(0.299)\end{array}$ & $\begin{array}{l}-0.044 \\
(0.294)\end{array}$ & $\begin{array}{c}0.048 \\
(0.309)\end{array}$ & $\begin{array}{l}-0.004 \\
(0.083)\end{array}$ & $\begin{array}{c}0.082 \\
(0.228)\end{array}$ \\
\hline Age (years) & $\begin{array}{c}-0.050 * * * \\
(0.011)\end{array}$ & $\begin{array}{c}-0.047 * * * \\
(0.011)\end{array}$ & $\begin{array}{c}-0.031 * * * \\
(0.011)\end{array}$ & $\begin{array}{c}-0.010 * * * \\
(0.003)\end{array}$ & $\begin{array}{c}-0.023 * * \\
(0.009)\end{array}$ \\
\hline Height & $\begin{array}{c}0.027 \\
(0.018)\end{array}$ & $\begin{array}{c}0.023 \\
(0.018)\end{array}$ & $\begin{array}{c}0.021 \\
(0.018)\end{array}$ & $\begin{array}{c}0.005 \\
(0.005)\end{array}$ & $\begin{array}{c}0.018 \\
(0.013)\end{array}$ \\
\hline $\begin{array}{l}\text { Log. consumption } \\
\text { (\$ PPP per AE) }\end{array}$ & & $\begin{array}{l}0.502 * \\
(0.257)\end{array}$ & $\begin{array}{c}0.237 \\
(0.300)\end{array}$ & $\begin{array}{c}0.051 \\
(0.082)\end{array}$ & $\begin{array}{c}0.164 \\
(0.219)\end{array}$ \\
\hline Education (years) & & & $\begin{array}{c}0.035 \\
(0.041)\end{array}$ & $\begin{array}{c}0.010 \\
(0.011)\end{array}$ & $\begin{array}{c}0.029 \\
(0.031)\end{array}$ \\
\hline Married & & & $\begin{array}{c}0.149 \\
(0.416)\end{array}$ & $\begin{array}{c}0.024 \\
(0.111)\end{array}$ & $\begin{array}{c}0.075 \\
(0.307)\end{array}$ \\
\hline Dependency ratio & & & $\begin{array}{l}-0.254 \\
(0.204)\end{array}$ & $\begin{array}{l}-0.056 \\
(0.056)\end{array}$ & $\begin{array}{l}-0.161 \\
(0.150)\end{array}$ \\
\hline Household size & & & $\begin{array}{c}0.040 \\
(0.068)\end{array}$ & $\begin{array}{c}0.010 \\
(0.018)\end{array}$ & $\begin{array}{c}0.029 \\
(0.049)\end{array}$ \\
\hline Self-employed & & & $\begin{array}{c}1.404 * * * \\
(0.456)\end{array}$ & $\begin{array}{c}0.353 * * * \\
(0.124)\end{array}$ & $\begin{array}{c}0.993 * * * \\
(0.336)\end{array}$ \\
\hline Unemployed & & & $\begin{array}{l}-0.669 \\
(0.645)\end{array}$ & $\begin{array}{l}-0.171 \\
(0.179)\end{array}$ & $\begin{array}{l}-0.500 \\
(0.451)\end{array}$ \\
\hline Civil servant & & & $\begin{array}{c}0.140 \\
(0.691)\end{array}$ & $\begin{array}{c}0.102 \\
(0.189)\end{array}$ & $\begin{array}{c}0.225 \\
(0.516)\end{array}$ \\
\hline $\begin{array}{l}\text { Subjective health } \\
\text { impairment }\end{array}$ & & & $\begin{array}{l}-0.096 \\
(0.404)\end{array}$ & $\begin{array}{l}-0.029 \\
(0.110)\end{array}$ & $\begin{array}{l}-0.069 \\
(0.294)\end{array}$ \\
\hline Optimism & & & $\begin{array}{l}0.323 * \\
(0.172)\end{array}$ & $\begin{array}{c}0.102 * * \\
(0.047)\end{array}$ & $\begin{array}{c}0.266^{* * *} \\
(0.130)\end{array}$ \\
\hline Constant & $\begin{array}{c}2.827 \\
(3.202) \\
\end{array}$ & $\begin{array}{c}2.545 \\
(3.168) \\
\end{array}$ & $\begin{array}{c}1.828 \\
(3.258) \\
\end{array}$ & & $\begin{array}{c}2.141 \\
(2.362) \\
\end{array}$ \\
\hline Log. sigma & $\begin{array}{c}1.332 * * * \\
(0.037)\end{array}$ & $\begin{array}{c}1.329 * * * \\
(0.037)\end{array}$ & $\begin{array}{c}1.316 * * * \\
(0.037)\end{array}$ & & \\
\hline (Pseudo-) R² & $(0.023)$ & $(0.027)$ & $(0.043)$ & $(0.016)$ & 0.056 \\
\hline Observations & 932 & 932 & 929 & 929 & 929 \\
\hline \multicolumn{6}{|c|}{$\begin{array}{l}\text { Notes: } \\
\text { Columns } 1-3 \text { report interval regression estimates of self-reported willingness to take risk on a 11-point Likert } \\
\text { scale. Column } 4 \text { reports ordered probit estimates with cut points and standard errors in square brackets as follows: } \\
\text { cut1: }-0.577(0.876) \text {, cut2: }-0.371(0.878) \text {, cut3: }-0.060(0.879) \text {, cut } 4: 0.111(0.882) \text {, cut5: } 0.246(0.882) \text {, cut6: } \\
1.370(0.873) \text {, cut7: } 1.456(0.874) \text {, cut8: } 1.561 *(0.877) \text {, cut } 9: 1.727 *(0.873) \text {, cut } 10: 1.764 * *(0.875) \text {. Column } 5 \\
\text { reports OLS estimates. All specifications take the complex sampling design into account. } \\
* * *, * * \text { and } * \text { denote significance at the } 1 \%, 5 \% \text { and } 10 \% \text { levels, respectively. }\end{array}$} \\
\hline
\end{tabular}


Table 3: Results of the experiment

\begin{tabular}{|c|c|c|c|c|c|c|c|c|}
\hline \multirow[t]{3}{*}{ Row } & \multirow{3}{*}{$\begin{array}{c}\text { Safe } \\
\text { amount }\end{array}$} & \multicolumn{2}{|c|}{ Lottery payoffs } & \multirow{3}{*}{$\begin{array}{l}\text { Frequency } \\
\text { (1) }\end{array}$} & \multirow{3}{*}{$\begin{array}{l}\text { Cumulative } \\
\text { relative } \\
\text { frequency } \\
\text { (2) }\end{array}$} & \multirow{3}{*}{\multicolumn{3}{|c|}{$\begin{array}{l}\text { Implied interval for the } \\
\text { coefficient of relative risk } \\
\text { aversion } r \\
\text { (3) }\end{array}$}} \\
\hline & & \multirow[t]{2}{*}{$\mathrm{p}_{0}=0.5$} & \multirow[t]{2}{*}{$\mathrm{p}_{1}=0.5$} & & & & & \\
\hline & & & & & & & & \\
\hline 1 & 0 & 0 & 300 & 40 & 0.043 & 0.796 & to & inf \\
\hline 2 & 10 & 0 & 300 & 234 & 0.295 & 0.744 & to & 0.796 \\
\hline 3 & 20 & 0 & 300 & 98 & 0.400 & 0.699 & to & 0.744 \\
\hline 4 & 30 & 0 & 300 & 68 & 0.473 & 0.656 & to & 0.699 \\
\hline 5 & 40 & 0 & 300 & 65 & 0.543 & 0.613 & to & 0.656 \\
\hline 6 & 50 & 0 & 300 & 63 & 0.611 & 0.569 & to & 0.613 \\
\hline 7 & 60 & 0 & 300 & 39 & 0.653 & 0.524 & to & 0.569 \\
\hline 8 & 70 & 0 & 300 & 35 & 0.690 & 0.476 & to & 0.524 \\
\hline 9 & 80 & 0 & 300 & 36 & 0.729 & 0.424 & to & 0.476 \\
\hline 10 & 90 & 0 & 300 & 34 & 0.766 & 0.369 & to & 0.424 \\
\hline 11 & 100 & 0 & 300 & 73 & 0.844 & 0.309 & to & 0.369 \\
\hline 12 & 110 & 0 & 300 & 10 & 0.855 & 0.244 & to & 0.309 \\
\hline 13 & 120 & 0 & 300 & 20 & 0.876 & 0.171 & to & 0.244 \\
\hline 14 & 130 & 0 & 300 & 5 & 0.882 & 0.091 & to & 0.171 \\
\hline 15 & 140 & 0 & 300 & 7 & 0.889 & 0 & to & 0.091 \\
\hline 16 & 150 & 0 & 300 & 17 & 0.908 & -0.103 & to & 0 \\
\hline 17 & 160 & 0 & 300 & 4 & 0.912 & -0.220 & to & -0.103 \\
\hline 18 & 170 & 0 & 300 & 4 & 0.916 & -0.357 & to & -0.220 \\
\hline 19 & 180 & 0 & 300 & 3 & 0.919 & -0.518 & to & -0.357 \\
\hline 20 & 190 & 0 & 300 & 75 & 1.000 & - inf & to & -0.518 \\
\hline
\end{tabular}

Observations: 930 
Table 4: Multivariate correlates of the experiment

\begin{tabular}{lccccc}
\hline & $(1)$ & $(2)$ & $(3)$ & $(4)$ & $(5)$ \\
\hline General willingness to & $0.266 * * *$ & $0.280 * * *$ & $0.257 * * *$ & $0.039 * * *$ & $0.228 * * *$ \\
take risk & $(0.070)$ & $(0.071)$ & $(0.069)$ & $(0.013)$ & $(0.062)$ \\
Female & & 0.294 & 0.111 & 0.045 & 0.144 \\
& & $(0.401)$ & $(0.442)$ & $(0.082)$ & $(0.414)$ \\
Age (years) & & 0.021 & 0.027 & 0.003 & 0.024 \\
& & $(0.016)$ & $(0.017)$ & $(0.003)$ & $(0.015)$ \\
Height & & 0.005 & -0.004 & -0.001 & -0.002 \\
& & $(0.030)$ & $(0.031)$ & $(0.005)$ & $(0.028)$ \\
Other controls & No & No & Yes & Yes & Yes \\
Constant & $5.760^{* * *}$ & 3.726 & 3.817 & & 3.756 \\
& $(0.365)$ & $(5.195)$ & $(5.218)$ & & $(4.839)$ \\
\hline Log. sigma & $1.780^{* * *}$ & $1.779 * * *$ & $1.771 * * *$ & & \\
& $(0.034)$ & $(0.034)$ & $(0.034)$ & & \\
\hline Sigma & 5.93 & 5.92 & 5.87 & & \\
(Pseudo-) R & $(0.015)$ & $(0.017)$ & $(0.025)$ & $(0.005)$ & 0.027 \\
Observations & 929 & 928 & 925 & 925 & 925 \\
\hline
\end{tabular}

Notes:

The dependent variable is the switching row in the experiment. Columns 1-3 report interval regression coefficient estimates and standard errors in brackets considering the complex sampling design.

Columns 4 and 5 report estimates of an ordered probit and OLS estimation, respectively, with the same independents as in column 3. Other controls include log per capita income, education (years of schooling), dependency ratio, household size, optimism and dummies for being married, selfemployed, unemployed and employed as a civil servant and subjective health impairment.

Cut points and standard errors in brackets of the ordered probit estimation are as follows: cut1: -1.402 (0.931), cut2: -0.212 (0.942), cut3: 0.080 (0.940), cut4: 0.269 (0.941), cut5: 0.447 (0.943), cut6: 0.623 (0.946), cut7: 0.737 (0.949), cut8: 0.840 (0.948), cut9: 0.955 (0.950), cut10: 1.072 (0.948), cut11: 1.362 (0.946), cut12: $1.410(0.947)$, cut13: 1.513 (0.945), cut14: $1.541(0.942)$, cut15: $1.581^{*}(0.939)$, cut16: $1.681 *(0.939)$, cut17: $1.708 *(0.939)$, cut18: $1.736 *(0.940)$, cut19: $1.758^{*}(0.943)$. ***, ** and $*$ denote significance at the $1 \%, 5 \%$ and $10 \%$ levels, respectively.. 
Table 5: Multivariate correlates of the experiment for subsamples

\begin{tabular}{|c|c|c|c|c|c|}
\hline & $\begin{array}{c}(1) \\
\text { Excl. subjects } \\
\text { choosing middle } \\
\text { category in } \\
\text { WTR }\end{array}$ & $\begin{array}{c}\text { (2) } \\
\text { Excl. subjects } \\
\text { choosing middle } \\
\text { category in WTR } \\
\text { or experiment }\end{array}$ & $\begin{array}{c}\text { (3) } \\
0-4 \text { years } \\
\text { of } \\
\text { schooling }\end{array}$ & $\begin{array}{c}(4) \\
5-6 \text { years } \\
\text { of } \\
\text { schooling }\end{array}$ & $\begin{array}{c}\text { (5) } \\
7 \text { or more } \\
\text { years of } \\
\text { schooling }\end{array}$ \\
\hline $\begin{array}{l}\text { General willingness } \\
\text { to take risk }\end{array}$ & $\begin{array}{c}0.280 * * * \\
(0.076)\end{array}$ & $\begin{array}{c}0.288 * * * \\
(0.077)\end{array}$ & $\begin{array}{c}0.258 * * * \\
(0.083)\end{array}$ & $\begin{array}{l}0.304^{*} \\
(0.171)\end{array}$ & $\begin{array}{c}0.376^{* *} \\
(0.161)\end{array}$ \\
\hline Female & $\begin{array}{l}-0.428 \\
(0.621)\end{array}$ & $\begin{array}{l}-0.496 \\
(0.628)\end{array}$ & $\begin{array}{c}0.293 \\
(0.583)\end{array}$ & $\begin{array}{c}1.711 \\
(1.328)\end{array}$ & $\begin{array}{l}-0.436 \\
(1.218)\end{array}$ \\
\hline Age (years) & $\begin{array}{c}0.025 \\
(0.021)\end{array}$ & $\begin{array}{c}0.026 \\
(0.021)\end{array}$ & $\begin{array}{c}0.008 \\
(0.025)\end{array}$ & $\begin{array}{c}0.161 * * * \\
(0.060)\end{array}$ & $\begin{array}{c}0.001 \\
(0.038)\end{array}$ \\
\hline Height $(\mathrm{cm})$ & $\begin{array}{c}0.035 \\
(0.038)\end{array}$ & $\begin{array}{c}0.035 \\
(0.039)\end{array}$ & $\begin{array}{c}0.013 \\
(0.038)\end{array}$ & $\begin{array}{c}0.025 \\
(0.078)\end{array}$ & $\begin{array}{l}-0.054 \\
(0.074)\end{array}$ \\
\hline Constant & $\begin{array}{l}-0.867 \\
(6.593)\end{array}$ & $\begin{array}{l}-0.880 \\
(6.709)\end{array}$ & $\begin{array}{c}3.254 \\
(6.458)\end{array}$ & $\begin{array}{c}-6.130 \\
(13.680)\end{array}$ & $\begin{array}{c}14.122 \\
(12.655)\end{array}$ \\
\hline Log. sigma & $\begin{array}{c}1.777 * * * \\
(0.042)\end{array}$ & $\begin{array}{c}1.785 * * * \\
(0.043)\end{array}$ & $\begin{array}{c}1.794 * * * \\
(0.031)\end{array}$ & $\begin{array}{c}1.735 * * * \\
(0.059)\end{array}$ & $\begin{array}{c}1.745^{* * *} \\
(0.059)\end{array}$ \\
\hline Pseudo-R ${ }^{2}$ & 0.032 & 0.034 & 0.015 & 0.048 & 0.030 \\
\hline Observations & 554 & 542 & 597 & 167 & 164 \\
\hline
\end{tabular}

Notes:

The table reports interval regression coefficient estimates and standard errors in brackets. The dependent variable is the switching row in the experiment. The estimates presented in column 1 differ from those presented in column 2 of table 4 by excluding subjects responding with the middle category for their general willingness to take risk. In column 2 those subjects choosing the central switching row in the experiment are excluded in addition. All estimations ignore the complex sample design, because some of the subsamples lead to clusters in single observations.

$* * *, * *$ and $*$ denote significance at the $1 \%, 5 \%$ and $10 \%$ levels, respectively.

Table 6: Spearman rank correlation of risk attitude measures for subsamples

\begin{tabular}{clc}
\hline & $\begin{array}{c}\text { General willingness to } \\
\text { take risk }\end{array}$ & $\begin{array}{c}\text { Switching row in } \\
\text { experiment }\end{array}$ \\
\hline Switching row in & a) $0.090^{* * *}$ & \\
experiment & b) $0.137^{* * *}$ & \\
& c) $0.242^{* * *}$ & \\
Amount invested in risky & a) $0.406^{* * *}$ & a) $0.061^{*}$ \\
asset (10.000 THB) & b) $0.438^{* * *}$ & b) $0.128^{* * *}$ \\
& c) $0.571^{* * *}$ & c) $0.163^{* * *}$ \\
\hline
\end{tabular}

Notes:

The table reports pairwise Spearman rank correlation coefficients for

a) the whole sample $(n=929)$,

b) excluding subjects choosing the central category for their willingness to take risk $(n=555)$

c) excluding subjects choosing a central category in any of the risk attitude measures $(n=352)$.

$* * *, * *$ and $*$ denote significance at the $1 \%, 5 \%$ and $10 \%$ levels, respectively. 
Table 7: Multivariate correlates of purchase of lottery tickets

\begin{tabular}{|c|c|c|c|c|c|c|c|}
\hline & (1) & (2) & (3) & (4) & (5) & (6) & $(7)$ \\
\hline $\begin{array}{l}\text { General willingness } \\
\text { to take risk }\end{array}$ & & $\begin{array}{c}0.023 * * * \\
(0.006)\end{array}$ & & $\begin{array}{c}0.022 * * * \\
(0.006)\end{array}$ & & $\begin{array}{c}0.019 * * * \\
(0.006)\end{array}$ & $\begin{array}{c}0.018 * * * \\
(0.006)\end{array}$ \\
\hline $\begin{array}{l}\text { Switching row in } \\
\text { experiment }\end{array}$ & & & $\begin{array}{l}0.006^{*} \\
(0.003)\end{array}$ & $\begin{array}{c}0.005 \\
(0.003)\end{array}$ & & & $\begin{array}{c}0.004 \\
(0.003)\end{array}$ \\
\hline $\begin{array}{l}\text { Amount invested in } \\
\text { risky asset }\end{array}$ & & & & & $\begin{array}{c}0.020 * * * \\
(0.006)\end{array}$ & $\begin{array}{l}0.012^{*} \\
(0.007)\end{array}$ & $\begin{array}{l}0.012 * \\
(0.007)\end{array}$ \\
\hline Female & $\begin{array}{l}-0.080^{*} \\
(0.042)\end{array}$ & $\begin{array}{c}-0.084 * * \\
(0.042)\end{array}$ & $\begin{array}{l}-0.083^{*} \\
(0.042)\end{array}$ & $\begin{array}{c}-0.086 * * \\
(0.043)\end{array}$ & $\begin{array}{l}-0.072 * \\
(0.042)\end{array}$ & $\begin{array}{l}-0.078 * \\
(0.043)\end{array}$ & $\begin{array}{l}-0.080^{*} \\
(0.043)\end{array}$ \\
\hline Age (years) & $\begin{array}{c}-0.004 * * * \\
(0.002)\end{array}$ & $\begin{array}{c}-0.004 * * \\
(0.002)\end{array}$ & $\begin{array}{c}-0.005 * * * \\
(0.002)\end{array}$ & $\begin{array}{c}-0.004 * * \\
(0.002)\end{array}$ & $\begin{array}{c}-0.004 * * \\
(0.002)\end{array}$ & $\begin{array}{c}-0.004 * * \\
(0.002)\end{array}$ & $\begin{array}{c}-0.004 * * \\
(0.002)\end{array}$ \\
\hline Height & $\begin{array}{l}-0.005^{*} \\
(0.003)\end{array}$ & $\begin{array}{c}-0.006 * * \\
(0.003)\end{array}$ & $\begin{array}{c}-0.005^{* *} \\
(0.003)\end{array}$ & $\begin{array}{c}-0.006 * * \\
(0.003)\end{array}$ & $\begin{array}{c}-0.005^{* *} \\
(0.003)\end{array}$ & $\begin{array}{c}-0.006 * * \\
(0.003)\end{array}$ & $\begin{array}{c}-0.006^{* *} \\
(0.003)\end{array}$ \\
\hline $\begin{array}{l}\text { Log. consumption } \\
\text { (\$PPP per AE) }\end{array}$ & $\begin{array}{c}0.144 * * * \\
(0.032)\end{array}$ & $\begin{array}{c}0.141 * * * \\
(0.032)\end{array}$ & $\begin{array}{c}0.143 * * * \\
(0.032)\end{array}$ & $\begin{array}{c}0.141 * * * \\
(0.032)\end{array}$ & $\begin{array}{c}0.137 * * * \\
(0.032)\end{array}$ & $\begin{array}{c}0.137 * * * \\
(0.032)\end{array}$ & $\begin{array}{c}0.138 * * * \\
(0.032)\end{array}$ \\
\hline Education (years) & $\begin{array}{c}0.004 \\
(0.006)\end{array}$ & $\begin{array}{c}0.003 \\
(0.006)\end{array}$ & $\begin{array}{c}0.003 \\
(0.006)\end{array}$ & $\begin{array}{c}0.002 \\
(0.006)\end{array}$ & $\begin{array}{c}0.004 \\
(0.006)\end{array}$ & $\begin{array}{c}0.004 \\
(0.006)\end{array}$ & $\begin{array}{c}0.003 \\
(0.006)\end{array}$ \\
\hline Married & $\begin{array}{c}0.064 \\
(0.047)\end{array}$ & $\begin{array}{c}0.064 \\
(0.047)\end{array}$ & $\begin{array}{c}0.074 \\
(0.047)\end{array}$ & $\begin{array}{c}0.073 \\
(0.048)\end{array}$ & $\begin{array}{c}0.057 \\
(0.047)\end{array}$ & $\begin{array}{c}0.059 \\
(0.047)\end{array}$ & $\begin{array}{c}0.068 \\
(0.048)\end{array}$ \\
\hline Dependency ratio & $\begin{array}{c}0.035 \\
(0.026)\end{array}$ & $\begin{array}{c}0.040 \\
(0.026)\end{array}$ & $\begin{array}{c}0.036 \\
(0.026)\end{array}$ & $\begin{array}{c}0.040 \\
(0.026)\end{array}$ & $\begin{array}{c}0.040 \\
(0.026)\end{array}$ & $\begin{array}{c}0.042 \\
(0.026)\end{array}$ & $\begin{array}{c}0.042 \\
(0.026)\end{array}$ \\
\hline Household size & $\begin{array}{c}0.009 \\
(0.010)\end{array}$ & $\begin{array}{c}0.009 \\
(0.010)\end{array}$ & $\begin{array}{c}0.009 \\
(0.010)\end{array}$ & $\begin{array}{c}0.008 \\
(0.010)\end{array}$ & $\begin{array}{c}0.009 \\
(0.010)\end{array}$ & $\begin{array}{c}0.009 \\
(0.010)\end{array}$ & $\begin{array}{c}0.008 \\
(0.010)\end{array}$ \\
\hline Unemployed & $\begin{array}{l}-0.034 \\
(0.085)\end{array}$ & $\begin{array}{l}-0.021 \\
(0.085)\end{array}$ & $\begin{array}{l}-0.016 \\
(0.085)\end{array}$ & $\begin{array}{l}-0.005 \\
(0.085)\end{array}$ & $\begin{array}{l}-0.022 \\
(0.085)\end{array}$ & $\begin{array}{l}-0.016 \\
(0.085)\end{array}$ & $\begin{array}{l}-0.000 \\
(0.085)\end{array}$ \\
\hline Self-employed & $\begin{array}{l}-0.006 \\
(0.054)\end{array}$ & $\begin{array}{l}-0.029 \\
(0.055)\end{array}$ & $\begin{array}{c}0.002 \\
(0.054)\end{array}$ & $\begin{array}{l}-0.019 \\
(0.055)\end{array}$ & $\begin{array}{l}-0.025 \\
(0.054)\end{array}$ & $\begin{array}{l}-0.036 \\
(0.055)\end{array}$ & $\begin{array}{l}-0.026 \\
(0.055)\end{array}$ \\
\hline Civil servant & $\begin{array}{l}-0.039 \\
(0.102)\end{array}$ & $\begin{array}{l}-0.044 \\
(0.102)\end{array}$ & $\begin{array}{l}-0.038 \\
(0.102)\end{array}$ & $\begin{array}{l}-0.042 \\
(0.102)\end{array}$ & $\begin{array}{l}-0.057 \\
(0.102)\end{array}$ & $\begin{array}{l}-0.053 \\
(0.102)\end{array}$ & $\begin{array}{l}-0.051 \\
(0.102)\end{array}$ \\
\hline $\begin{array}{l}\text { Subjective health } \\
\text { impairment }\end{array}$ & $\begin{array}{c}0.020 \\
(0.047)\end{array}$ & $\begin{array}{c}0.022 \\
(0.048)\end{array}$ & $\begin{array}{c}0.015 \\
(0.048)\end{array}$ & $\begin{array}{c}0.017 \\
(0.048)\end{array}$ & $\begin{array}{c}0.015 \\
(0.048)\end{array}$ & $\begin{array}{c}0.018 \\
(0.048)\end{array}$ & $\begin{array}{c}0.014 \\
(0.048)\end{array}$ \\
\hline Optimism & $\begin{array}{l}-0.007 \\
(0.020)\end{array}$ & $\begin{array}{l}-0.013 \\
(0.020)\end{array}$ & $\begin{array}{l}-0.006 \\
(0.020)\end{array}$ & $\begin{array}{l}-0.012 \\
(0.021)\end{array}$ & $\begin{array}{l}-0.009 \\
(0.020)\end{array}$ & $\begin{array}{l}-0.013 \\
(0.020)\end{array}$ & $\begin{array}{l}-0.012 \\
(0.021)\end{array}$ \\
\hline Pseudo $\mathrm{R}^{2}$ & 0.03 & 0.05 & 0.04 & 0.05 & 0.04 & 0.05 & 0.05 \\
\hline Observations & 929 & 929 & 925 & 925 & 929 & 929 & 925 \\
\hline
\end{tabular}

Notes:

The dependent, purchase of lottery tickets, takes the value of 1 if the household reports expenditures for lottery tickets and zero otherwise. The table reports marginal effects at the mean $(0.50)$ and standard errors in brackets of probit regressions considering the complex sampling design. ***, ** and $*$ denote significance at the $1 \%, 5 \%$ and $10 \%$ levels, respectively. 
Table 8: Multivariate correlates of being self-employed

\begin{tabular}{|c|c|c|c|c|c|c|c|}
\hline & $(1)$ & $(2)$ & (3) & $(4)$ & $(5)$ & $(6)$ & $(7)$ \\
\hline $\begin{array}{l}\text { General willingness to } \\
\text { take risk }\end{array}$ & & $\begin{array}{l}0.010 * * * \\
(0.003)\end{array}$ & & $\begin{array}{l}0.011 * * * \\
(0.003)\end{array}$ & & $\begin{array}{l}0.007^{*} \\
(0.003)\end{array}$ & $\begin{array}{l}0.007^{*} \\
(0.003)\end{array}$ \\
\hline $\begin{array}{l}\text { Switching row in } \\
\text { experiment }\end{array}$ & & & $\begin{array}{c}0.000 \\
(0.002)\end{array}$ & $\begin{array}{l}-0.001 \\
(0.002)\end{array}$ & & & $\begin{array}{l}-0.001 \\
(0.002)\end{array}$ \\
\hline $\begin{array}{l}\text { Amount invested in risky } \\
\text { asset }(10.000 \mathrm{THB})\end{array}$ & & & & & $\begin{array}{c}0.013 * * * \\
(0.003)\end{array}$ & $\begin{array}{c}0.010 * * * \\
(0.003)\end{array}$ & $\begin{array}{c}0.010 * * * \\
(0.003)\end{array}$ \\
\hline Female & $\begin{array}{c}0.002 \\
(0.026)\end{array}$ & $\begin{array}{l}-0.003 \\
(0.025)\end{array}$ & $\begin{array}{l}-0.000 \\
(0.026)\end{array}$ & $\begin{array}{l}-0.005 \\
(0.025)\end{array}$ & $\begin{array}{c}0.006 \\
(0.025)\end{array}$ & $\begin{array}{c}0.001 \\
(0.025)\end{array}$ & $\begin{array}{l}-0.001 \\
(0.025)\end{array}$ \\
\hline Age (years) & $\begin{array}{c}-0.002 * * \\
(0.001)\end{array}$ & $\begin{array}{c}-0.002 * * \\
(0.001)\end{array}$ & $\begin{array}{c}-0.002 * * \\
(0.001)\end{array}$ & $\begin{array}{c}-0.002 * * \\
(0.001)\end{array}$ & $\begin{array}{c}-0.002 * * \\
(0.001)\end{array}$ & $\begin{array}{c}-0.002 * * \\
(0.001)\end{array}$ & $\begin{array}{c}-0.002 * * \\
(0.001)\end{array}$ \\
\hline Height & $\begin{array}{l}-0.000 \\
(0.001)\end{array}$ & $\begin{array}{l}-0.001 \\
(0.001)\end{array}$ & $\begin{array}{l}-0.000 \\
(0.001)\end{array}$ & $\begin{array}{l}-0.001 \\
(0.001)\end{array}$ & $\begin{array}{l}-0.001 \\
(0.001)\end{array}$ & $\begin{array}{l}-0.001 \\
(0.001)\end{array}$ & $\begin{array}{l}-0.001 \\
(0.001)\end{array}$ \\
\hline $\begin{array}{l}\text { Log. consumption } \\
\text { (\$PPP per AE) }\end{array}$ & $\begin{array}{c}0.094 * * * \\
(0.022)\end{array}$ & $\begin{array}{c}0.091 * * * \\
(0.023)\end{array}$ & $\begin{array}{c}0.092 * * * \\
(0.022)\end{array}$ & $\begin{array}{c}0.089 * * * \\
(0.023)\end{array}$ & $\begin{array}{c}0.086 * * * \\
(0.022)\end{array}$ & $\begin{array}{l}0.086 * * * \\
(0.023)\end{array}$ & $\begin{array}{c}0.084 * * * \\
(0.023)\end{array}$ \\
\hline Education (years) & $\begin{array}{l}-0.001 \\
(0.004)\end{array}$ & $\begin{array}{l}-0.002 \\
(0.003)\end{array}$ & $\begin{array}{l}-0.001 \\
(0.004)\end{array}$ & $\begin{array}{l}-0.001 \\
(0.004)\end{array}$ & $\begin{array}{l}-0.001 \\
(0.004)\end{array}$ & $\begin{array}{l}-0.002 \\
(0.004)\end{array}$ & $\begin{array}{l}-0.001 \\
(0.004)\end{array}$ \\
\hline Married & $\begin{array}{l}-0.058^{*} \\
(0.032)\end{array}$ & $\begin{array}{c}-0.059 * * \\
(0.032)\end{array}$ & $\begin{array}{c}-0.062 * * \\
(0.032)\end{array}$ & $\begin{array}{l}-0.063 * * \\
(0.032)\end{array}$ & $\begin{array}{l}-0.067 * * \\
(0.034)\end{array}$ & $\begin{array}{l}-0.065^{* *} \\
(0.033)\end{array}$ & $\begin{array}{c}-0.069 * * \\
(0.033)\end{array}$ \\
\hline Dependency ratio & $\begin{array}{l}-0.010 \\
(0.014)\end{array}$ & $\begin{array}{l}-0.008 \\
(0.014)\end{array}$ & $\begin{array}{c}-0.011 \\
(0.014)\end{array}$ & $\begin{array}{l}-0.009 \\
(0.014)\end{array}$ & $\begin{array}{l}-0.006 \\
(0.014)\end{array}$ & $\begin{array}{l}-0.006 \\
(0.014)\end{array}$ & $\begin{array}{l}-0.006 \\
(0.014)\end{array}$ \\
\hline Household size & $\begin{array}{c}0.004 \\
(0.006)\end{array}$ & $\begin{array}{c}0.004 \\
(0.006)\end{array}$ & $\begin{array}{c}0.004 \\
(0.006)\end{array}$ & $\begin{array}{c}0.005 \\
(0.006)\end{array}$ & $\begin{array}{c}0.004 \\
(0.006)\end{array}$ & $\begin{array}{c}0.004 \\
(0.006)\end{array}$ & $\begin{array}{c}0.004 \\
(0.006)\end{array}$ \\
\hline Subjective Health status & $\begin{array}{l}-0.010 \\
(0.029)\end{array}$ & $\begin{array}{l}-0.007 \\
(0.030)\end{array}$ & $\begin{array}{l}-0.009 \\
(0.029)\end{array}$ & $\begin{array}{c}-0.005 \\
(0.030)\end{array}$ & $\begin{array}{l}-0.011 \\
(0.028)\end{array}$ & $\begin{array}{l}-0.008 \\
(0.030)\end{array}$ & $\begin{array}{c}-0.007 \\
(0.030)\end{array}$ \\
\hline Optimism & $\begin{array}{l}-0.014 * \\
(0.009)\end{array}$ & $\begin{array}{l}-0.016^{*} \\
(0.009)\end{array}$ & $\begin{array}{l}-0.016^{*} \\
(0.009)\end{array}$ & $\begin{array}{c}-0.018 * * \\
(0.009)\end{array}$ & $\begin{array}{l}-0.015^{*} \\
(0.009)\end{array}$ & $\begin{array}{l}-0.016^{*} \\
(0.009)\end{array}$ & $\begin{array}{c}-0.018^{* *} \\
(0.009)\end{array}$ \\
\hline Pseudo $\mathrm{R}^{2}$ & 0.08 & 0.09 & 0.08 & 0.09 & 0.09 & 0.10 & 0.10 \\
\hline Observations & 929 & 929 & 925 & 925 & 929 & 929 & 925 \\
\hline
\end{tabular}

Notes:

The dependent takes the value of 1 if the respondent reports to be self-employed as the primary occupation and zero otherwise. The table reports marginal effects at the mean and standard errors in brackets of probit regressions considering the complex sampling design. All specifications include a constant, which is insignificant throughout and therefore not printed here. $* * *, * *$ and $*$ denote significance at the $1 \%, 5 \%$ and $10 \%$ levels, respectively. 


\section{Figure 1: Responses to self-assessment of general risk attitude}

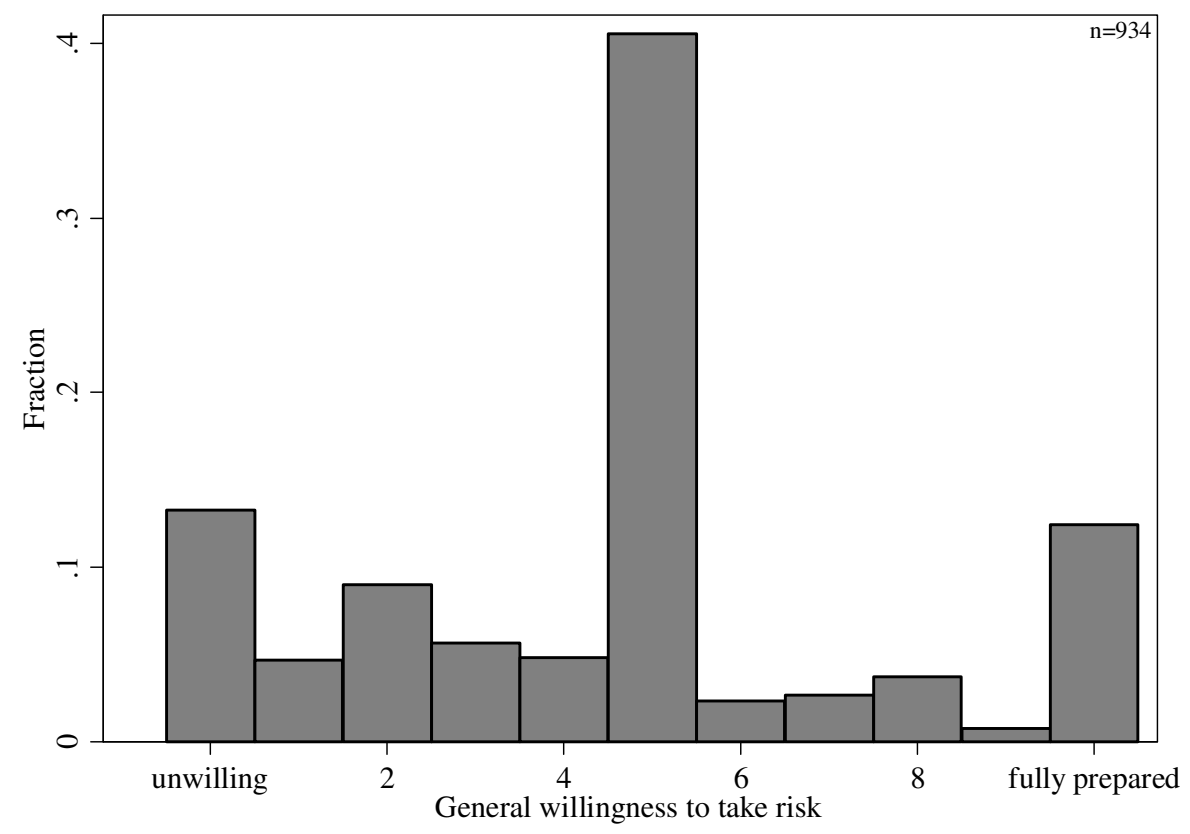

Notes:

Responses to the survey question: "Are you generally a person who is fully prepared to take risks or do you try to avoid taking risk? Please choose a number on a scale from 0 (unwilling to take risk) to 10 (fully prepared to take risk)".

Figure 2: Switching row in experiment by self-assessment of willingness to take risk

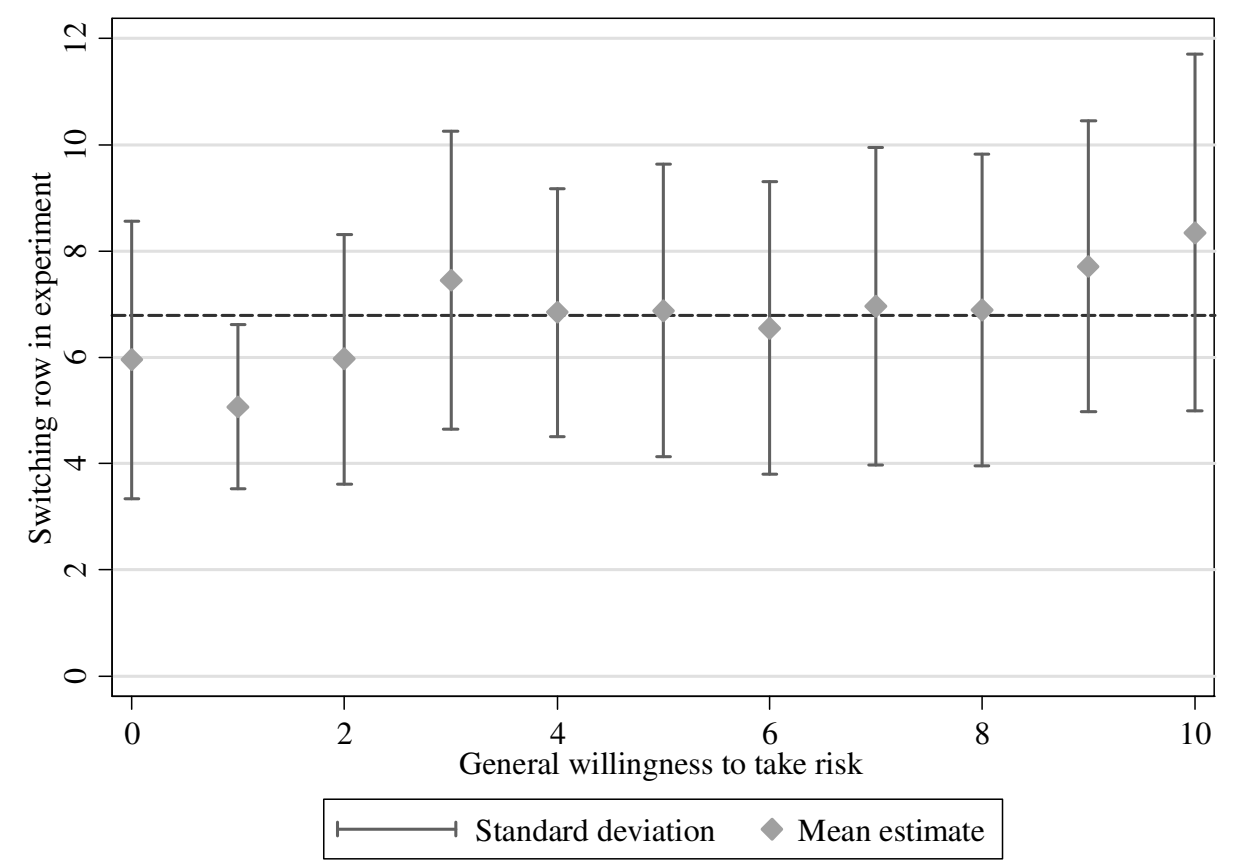

Notes:

The figure shows mean and standard deviation estimates for the switching row in the experiment by self-assessment of willingness to take risk considering the complex sampling design. The dashed line represents the overall mean switching row. 


\section{Figure 3: Amount invested in risky asset}

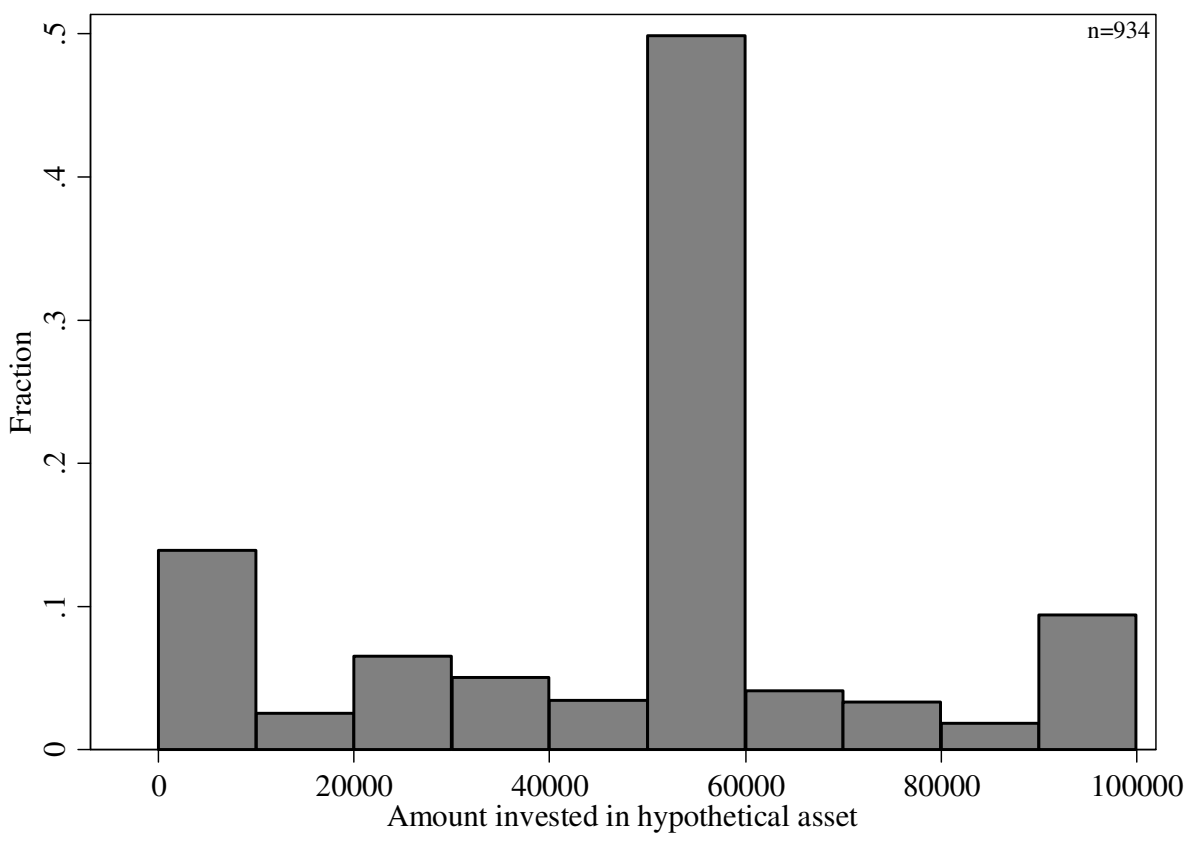

Notes:

Responses to the survey question: "Imagine you had just won 100,000 Baht in a lottery and you can invest this money in a business. It is equally likely that the business goes well or not. If it goes well you can double the amount invested after one year. If it does not go well you will lose half the amount you invested. What fraction of the 100,000 Baht would you invest in the business?" 
Appendix 1: Multivariate correlates of purchase of lottery tickets for respondents, who are household heads

\begin{tabular}{lccccccc}
\hline & $(1)$ & $(2)$ & $(3)$ & $(4)$ & $(5)$ & $(6)$ & $(7)$ \\
\hline General willingness to & & $0.025^{* * *}$ & & $0.024^{* * *}$ & & $0.021^{* *}$ & $0.020^{* *}$ \\
take risk & & $(0.008)$ & & $(0.008)$ & & $(0.009)$ & $(0.009)$ \\
Switching row in & & & 0.005 & 0.004 & & & 0.004 \\
experiment & & & $(0.004)$ & $(0.004)$ & & & $(0.004)$ \\
Amount invested in risky & & & & & $0.020^{* *}$ & 0.011 & 0.011 \\
asset (10.000 THB) & & & & & $(0.008)$ & $(0.009)$ & $(0.009)$ \\
Female & $-0.149^{* *}$ & $-0.159^{* *}$ & $-0.160^{* *}$ & $-0.169^{* * *}$ & $-0.139^{* *}$ & $-0.151^{* *}$ & $-0.162^{* *}$ \\
& $(0.064)$ & $(0.064)$ & $(0.064)$ & $(0.064)$ & $(0.064)$ & $(0.064)$ & $(0.064)$ \\
Age (years) & -0.003 & -0.002 & -0.003 & -0.003 & -0.002 & -0.002 & -0.002 \\
& $(0.002)$ & $(0.002)$ & $(0.002)$ & $(0.002)$ & $(0.002)$ & $(0.002)$ & $(0.002)$ \\
Height & $-0.008^{* *}$ & $-0.009^{* *}$ & $-0.008^{* *}$ & $-0.009 * * *$ & $-0.008^{* *}$ & $-0.009 * *$ & $-0.009^{* *}$ \\
& $(0.004)$ & $(0.004)$ & $(0.004)$ & $(0.004)$ & $(0.004)$ & $(0.004)$ & $(0.004)$ \\
Log. consumption & $0.117^{* * *}$ & $0.111^{* * *}$ & $0.118^{* * *}$ & $0.113 * * *$ & $0.109^{* * *}$ & $0.108^{* * *}$ & $0.110^{* * *}$ \\
(\$PPP per AE) & $(0.041)$ & $(0.041)$ & $(0.041)$ & $(0.042)$ & $(0.041)$ & $(0.041)$ & $(0.042)$ \\
Education (years) & 0.011 & 0.010 & 0.011 & 0.010 & 0.012 & 0.011 & 0.010 \\
& $(0.008)$ & $(0.008)$ & $(0.008)$ & $(0.008)$ & $(0.008)$ & $(0.008)$ & $(0.008)$ \\
Other controls & $\mathrm{n} . \mathrm{s}$. & $\mathrm{n} . \mathrm{s}$. & $\mathrm{n} . \mathrm{s}$. & $\mathrm{n} . \mathrm{s}$. & $\mathrm{n} . \mathrm{s}$. & $\mathrm{n} . \mathrm{s}$. & $\mathrm{n} . \mathrm{s}$. \\
Constant & $*$ & $*$ & $*$ & $* *$ & $*$ & $*$ & $*$ \\
\hline Pseudo-R & 0.04 & 0.06 & 0.05 & 0.06 & 0.05 & 0.06 & 0.06 \\
Observations & 517 & 517 & 514 & 514 & 517 & 517 & 514 \\
\hline
\end{tabular}

Notes:

Purchase of lottery tickets takes the value of 1 if the household reports expenditures for lottery tickets and zero otherwise. The probit regressions include only respondents who are concurrently head of the household. The table reports marginal effects at the mean (0.52) and standard errors in brackets of a probit regression ignoring the complex sampling design, because the reduced sample leads to clusters with single observations. $* * *, * *$ and $*$ denote significance at the $1 \%, 5 \%$ and $10 \%$ levels, respectively. Other controls include: education (years of schooling), dependency ratio, household size, optimism and dummies for being married, self-employed, unemployed and employed as a civil servant and subjective health impairment, none of which is significant. 
Appendix 2: Multivariate correlates of the experiment using the negative of the coefficient of relative risk aversion from the experiment as dependent variable

\begin{tabular}{lccccc}
\hline & $(1)$ & $(2)$ & $(3)$ & $(4)$ & $(5)$ \\
\hline General willingness to & $0.020^{* * *}$ & $0.021 * * *$ & $0.019 * * *$ & $0.039 * * *$ & $0.023^{* * *}$ \\
take risk & $(0.005)$ & $(0.005)$ & $(0.005)$ & $(0.013)$ & $(0.006)$ \\
Female & & 0.009 & -0.004 & 0.045 & -0.010 \\
& & $(0.027)$ & $(0.030)$ & $(0.082)$ & $(0.035)$ \\
Age (years) & & 0.001 & 0.002 & 0.003 & 0.002 \\
& & $(0.001)$ & $(0.001)$ & $(0.003)$ & $(0.001)$ \\
Height & & -0.000 & -0.001 & -0.001 & -0.001 \\
& & $(0.002)$ & $(0.002)$ & $(0.005)$ & $(0.002)$ \\
Further controls & No & No & Yes & Yes & Yes \\
Constant & $-0.590^{* * *}$ & $-0.646^{*}$ & $-0.641 *$ & & 0.624 \\
& $(0.025)$ & $(0.352)$ & $(0.351)$ & & $(0.410)$ \\
\hline Log. sigma & $-0.895 * * *$ & $-0.895 * * *$ & $-0.905 * * *$ & & \\
& $(0.043)$ & $(0.043)$ & $(0.044)$ & & \\
\hline Sigma & 0.41 & 0.41 & 0.40 & & \\
(Pseudo-) R ${ }^{2}$ & $(0.017)$ & $(0.018)$ & $(0.027)$ & $(0.005)$ & 0.033 \\
Observations & 929 & 928 & 925 & 925 & 925 \\
\hline
\end{tabular}

Notes:

The dependent variable is the coefficient of relative risk aversion from the experiment multiplied by -1 . Columns 1-3 report interval regression coefficient estimates and standard errors in brackets using the intervals reported in Table and considering the complex sampling design. Columns 4 and 5 report estimates of an ordered probit and OLS estimation using the midpoints of the intervals and -1 and 1 for the unbounded intervals, respectively. Specifications in columns 3 to 5 further include log per capita income, education (years of schooling), dependency ratio, household size, optimism and dummies for being married, self-employed, unemployed and employed as a civil servant and subjective health impairment. Different from results in table 4, the positive coefficient of log consumption becomes significant at the $10 \%$ level in the OLS model in column 5.

Cut points and standard errors in brackets of the ordered probit estimation in column 4 are as follows: cut 1: -1.402 (0.931), cut2: -0.212 (0.942), cut3: 0.080 (0.940), cut4: 0.269 (0.941), cut5: 0.447 (0.943), cut6: 0.623 (0.946), cut7: 0.737 (0.949), cut8: 0.840 (0.948), cut9: 0.955 (0.950), cut10: 1.072 (0.948), cut11: 1.362 (0.946), cut12: 1.410 (0.947), cut13: 1.513 (0.945), cut14: 1.541 (0.942), cut15 1.581* (0.939), cut16: $1.681 *(0.939)$, cut17: $1.708 *(0.939)$, cut18: $1.736 *(0.940)$, cut19: $1.758 *$ $(0.943)$. 
Appendix 3: Multivariate correlates of behavioral indicators using the negative of the relative risk aversion coefficient from the experiment as an explanatory variable

\begin{tabular}{|c|c|c|}
\hline Dependent variable & $\begin{array}{l}\text { Purchase of lottery } \\
\text { tickets }\end{array}$ & $\begin{array}{l}\text { Being self- } \\
\text { employed }\end{array}$ \\
\hline General willingness to take risk & $\begin{array}{c}0.022 * * * \\
(0.006)\end{array}$ & $\begin{array}{c}0.011 * * * \\
(0.003)\end{array}$ \\
\hline Negative of coefficient of RRA & $\begin{array}{c}0.048 \\
(0.035)\end{array}$ & $\begin{array}{l}-0.013 \\
(0.020)\end{array}$ \\
\hline Female & $\begin{array}{c}-0.085^{* *} \\
(0.043)\end{array}$ & $\begin{array}{l}-0.005 \\
(0.025)\end{array}$ \\
\hline Age (years) & $\begin{array}{c}-0.004 * * \\
(0.002)\end{array}$ & $\begin{array}{c}-0.002 * * \\
(0.001)\end{array}$ \\
\hline Height $(\mathrm{cm})$ & $\begin{array}{c}-0.006 * * \\
(0.003)\end{array}$ & $\begin{array}{l}-0.001 \\
(0.002)\end{array}$ \\
\hline $\begin{array}{l}\text { Log. consumption } \\
\text { (\$PPP per AE) }\end{array}$ & $\begin{array}{c}0.140 * * * \\
(0.032)\end{array}$ & $\begin{array}{c}0.090 * * * \\
(0.017)\end{array}$ \\
\hline Education (years) & $\begin{array}{c}0.002 \\
(0.006)\end{array}$ & $\begin{array}{l}-0.001 \\
(0.003)\end{array}$ \\
\hline Married & $\begin{array}{c}0.073 \\
(0.048)\end{array}$ & $\begin{array}{c}-0.063 * * \\
(0.033)\end{array}$ \\
\hline Dependency ratio & $\begin{array}{c}0.041 \\
(0.026)\end{array}$ & $\begin{array}{l}-0.009 \\
(0.017)\end{array}$ \\
\hline Household size & $\begin{array}{c}0.008 \\
(0.010)\end{array}$ & $\begin{array}{c}0.005 \\
(0.006)\end{array}$ \\
\hline Unemployed & $\begin{array}{l}-0.008 \\
(0.085)\end{array}$ & \\
\hline Self-employed & $\begin{array}{l}-0.018 \\
(0.055)\end{array}$ & \\
\hline Civil servant & $\begin{array}{l}-0.040 \\
(0.102)\end{array}$ & \\
\hline Subjective health impairment & $\begin{array}{c}0.018 \\
(0.048)\end{array}$ & $\begin{array}{l}-0.005 \\
(0.028)\end{array}$ \\
\hline Optimism & $\begin{array}{l}-0.012 \\
(0.021)\end{array}$ & $\begin{array}{l}-0.018 \\
(0.012)\end{array}$ \\
\hline Constant & n.s. & n.s. \\
\hline (Pseudo) $\mathrm{R}^{2}$ & 0.05 & $(0.09)$ \\
\hline Observations & 925 & 925 \\
\hline
\end{tabular}

Notes: The table presents alternative specifications for those shown in the last columns of tables 6 to 8 , which use the negative of the coefficient of relative risk aversion from the experiment instead of the switching row as an explanatory variable. The first column reports coefficients and standard errors in brackets of an OLS regression and corresponds to column (6) in table 6. The second and third columns report marginal effects and standard errors in brackets of probit regressions and correspond to column (6) in table 7 and table 8 , respectively. $* * * * *$ and $*$ denote significance at the $1 \%, 5 \%$ and $10 \%$ levels, respectively. 